\title{
الوقفة، شهود الأُحَدية:شلظة النفري الصوفية
}

\author{
آمال محمد عامر 1 \\ كلية الآداب- جامعة مصراتة
}
تاريخ التقديم: 19-12-2019 ، تاريخ القبول: 01-02- 2020، نشر إلكترونيا في 03-02-2020 https://doi.org/10.36602/faj/2020.n15.03

\section{ملخص البحث:}

يتناول البحث بحربة النفري الصوفية، من خلال لحظته الصوفية الشهودية في حال الفناء، والتي عبَّر عنها في نصوصه "المواقف" فكانت الوقفة هي لحظة النفري الصوفية الشهودية، والتي تجلت من خلال البناء اللغوي، والخطابي الحواري المتفرد عند النفري عن غيره من الصوفية، حيث جاءت على شكل ومضات مكثفة في دلالتها، لتعبّر عن حال الفناء

$$
\text { الشهودي، والتجليات على قلب الصوفي }
$$

الكلمات المفتاحية: التجلي، الواردات، المقام

Amal.amer@art.misuratau.edu.ly ${ }^{1}$ 


\title{
AL-WAQFAH, THE STATION OF DIVINE REVELATION OF THE SUFI AL- NIFFARĪ
}

\author{
Amal Amer \\ School of Arts -Misurata University
}

\section{Abstract}

The research deals with the experience of Al- Niffarī Sufism, through his station of the Sufi witness in the event of Fana or (Dissolution of the Ego), which he expressed in his texts "Al-Mawāqif", thus station or spiritual standing is the apocalyptic vision and the eschatological revelation, and the polarity of the experience of divine unity, found expression in construction of language and solely self conversational discourse, Formed intense flashes in its significance, to express the state of "Fanā" and the manifestations on the mystic heart

Keywords: manifestation, Warridat (Gifts and Favor), Maqaamat.

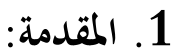

إن التجربة الصوفية في جوهرها هي سفر المؤمن الروحي إلى أعلى مستويات شهوده

في معارج الروح، وفي تجربة النفري تتداخل التجربة والكتابة، حيث تعد الوقفة وكذلك المخاطبة وهي الوجه الآخر للوقفة، من مؤلفات النفري التي كتبها من داخل التجربة الصوفية كممارسة نصية، ومن عمق تجربته الروحية في سفره وتوقه نحو القرب من الحق تعالى. ومن خلال هذا البحث فإننا نحاول استجلاء لحظة النفري الصوفية من داخل نصوصه الوقفة والمخاطبات، لتكون قراءة حية وسفراً نحو تخوم التجليات النورانية في عالم

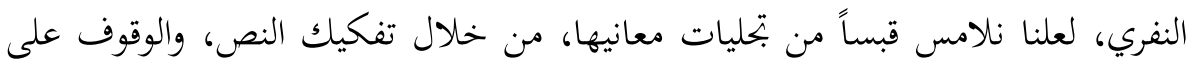
خصوصيته واستبصار دلالاته، ليتحقق ذلك الوصال وتنكشف حجب المعاني، عبر سفر في روحانية النص، وقراءة نستكشف فيها الذات الصوفية الصافية في توقها للمطلق، وسفرها في معارج الحب الإلهي. 


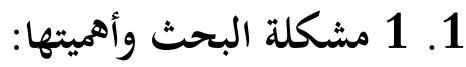

تأتي إثكالية الدراسة من خصوصية النص الصوفي النفري، حتى أنه يصعب على النى الكثيرين الاقتراب منه، على مستوى الموضوع وخصوصية بنائه اللغوي والمضامين الصوفية.

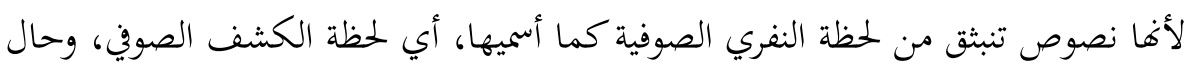

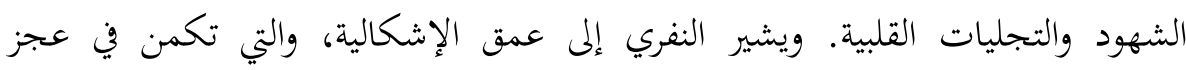

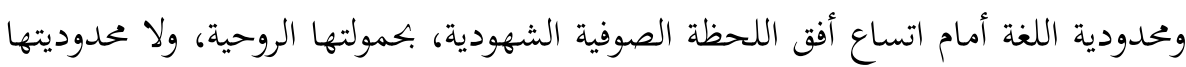

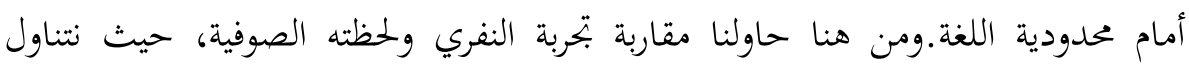

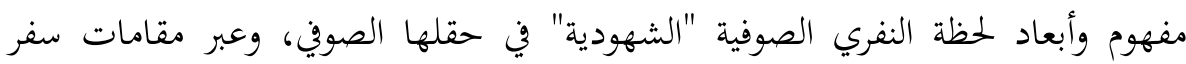
الحب الإلمي، ونسلط الضوء على خصوصية ودلالات مفهوم الوقفة في خطاب النفري،

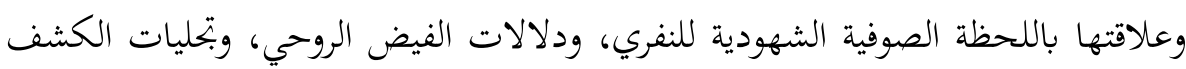

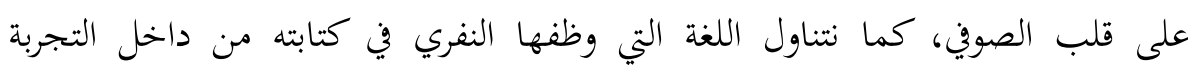

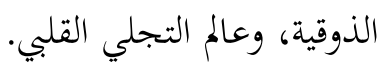

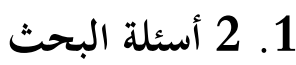

• كيف ارتبط نص النفري ولغته في الوقفة والمخاطبات، بلحظة النفري الصوفية الشهودية؟

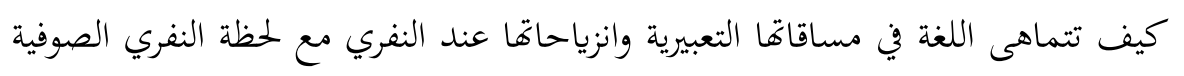

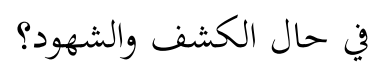

هيف تقاطعت نصوص النفري مع القرآن الكريم والحديث القدسي عبر فاعلية الحوار

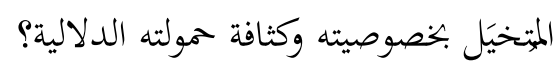

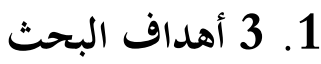

الوقوف على تجربة النفري من خلال لحظته الصوفية الشهودية، التي عبَّ عنها في

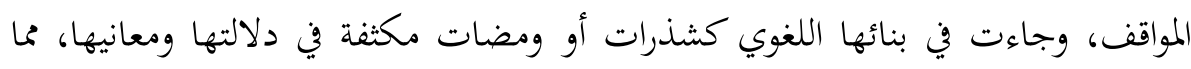
تطلب قراءة تأويلية، من أجل ملامسة معانيها. 


\section{2. المنهج والإجراءات}

اعتمدنا في هذه الدراسة على المنهج التحليلي الاستقرائي، وذلك بتتبع لحظة النغري الصوفية "الحالة الشهودية" في النص النفري، عبر مقاربة تعتمد التفكيك والتحليل، وتتبع لغة النفري في بنائها المتفرد ومحاولتها أن تستوعب تجليات الصوفي القلبية، وإشارات الواردات الإلهية في حال الكشف.

\section{3. الوقفة:مفهومها وخصائصها عند النفري}

3. 1 الوقفة في الاصطلاح اللغوي: "من وقف، وجمعها وقفات، وقفة السائر: استراحته

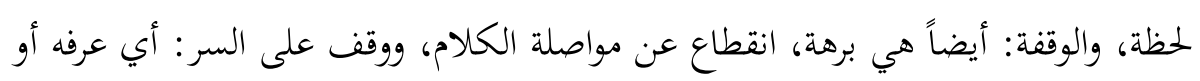

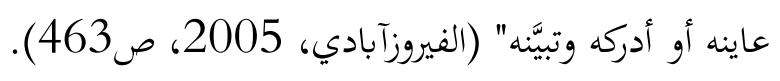

3. 1 الوقفة في الاصطلاح الصوفي:-يقول عفيف الدين التلمساني في المعنى الصوفي للوقفة: "أوقفني: أي أيقظ قابليتي لتلقي التجلي، وأوقفني: أي عرَّفني." (التلمساني، 2007

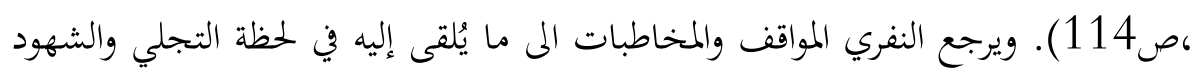

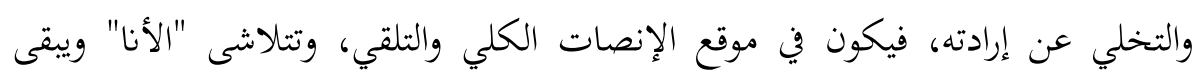

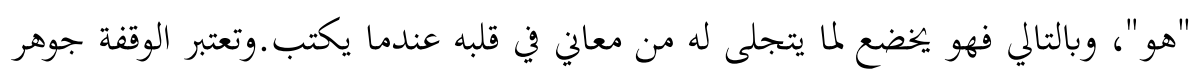

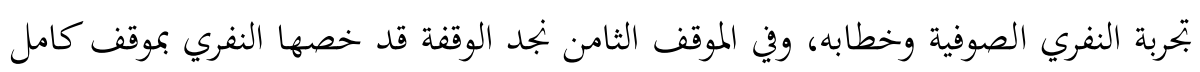
عنوانه" موقف الوقفة". والوقفة عند النفري هي وقفات أمام الله تعالى، تنطوي على حقيقة الموافقة لله، والاستجابة للحق تعالى. وبالتالي فهي المقام الأسمى في المعراج الصوفي الى الله، فالعارف غاية وقفته التي يصل إليها أن تشرق على قلبه الأنوار الإلهية، فيشعر أن وجوده صار أعلى وأسمى.

قال حسن حنفي بعد أن تسآل "ومن هو صاحب الموقف؟ هل هو الانسان، فالإنسان في موقف والانسان في العالم أم أن الله هو الذي يضع الانسان فيه ، ثم أجاب: 
الغالب هو الله نظرا لتكرار فعل (أوقفني ) في أول كل موقف" (حنفي،2009، ص (109

فالوقفة هي حال الفناء في الشهود، بعد أن تنقشع عتمة الأغيار ويصير السوى عدماً في قلب الصوفي، وهي منتهى ما يصل إليه العارف في سفره الروحي إلى الله، فيفنى في الحق، ويبقى بالحق تعالى. "وقال لي: الوقفة نورية تعرف القيم و تطمس الخواطر، وقال

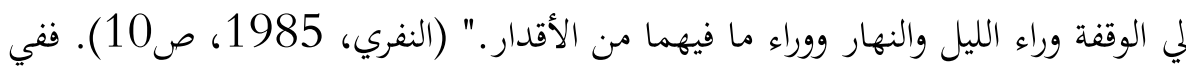
مقام الوقفة تتلاشى الغيرية والسوى من قلب الصوفي، ويتجاوز الصوفي بقلبه ويتعالى عن

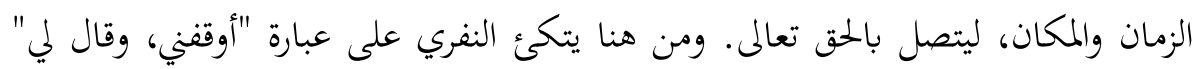

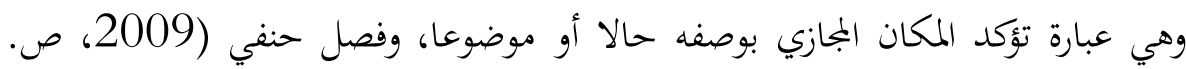

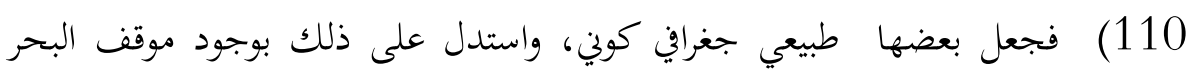
وموقف النور والليل بحيث تصعب التفرقة بين الله والطبيعة ، وقال في الوقفة إها تعني المنظور الإلهي ،الوقوف مع الله، الرؤية الإلهية مما يدل على أن صاحب الموقف هو الله. وتحضر صيغة الماضي في "أوقفني، وقال لي" منفتحة على دلالة الزمان المطلق،

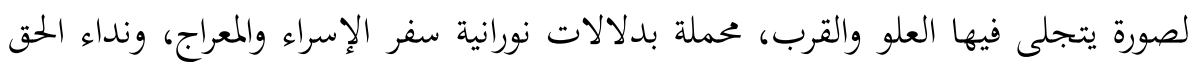

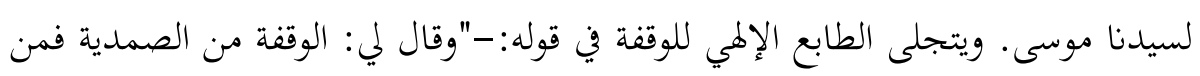

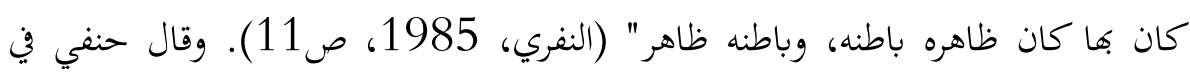

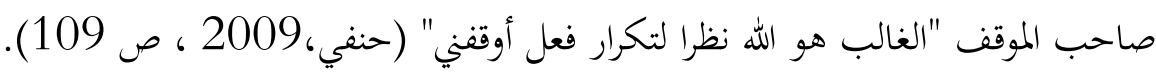
والصمدية صفة إلهية غخصوصة تتعلق بالذات الإلهية وحدها. ويستشعر العارف استيلاء الوجود الإلهي هنا على كل ما عداه، وحضور الحق في كل مكان وزمان، فتتلاشى المسافات شعوريا في قلب العارف مع الحق تعالى لذلك كان زمان العارف الواقف حضور دائم وشعور بمعية الله في قلب المؤمن. ويمكن القول أنه من أهم بتحليات ومقتضيات الوقفة هو الصمت الذي يصير مقام تلقي من العارف للخطاب، منطويا على دلالة عجز العبارة 
أمام اتساع الرؤيا، ذلك أن المخاطِب هو الحق تعالى، ومن هنا اقتضى جلاله وكماله أن

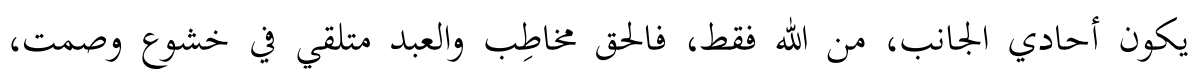

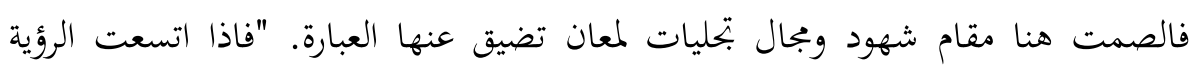

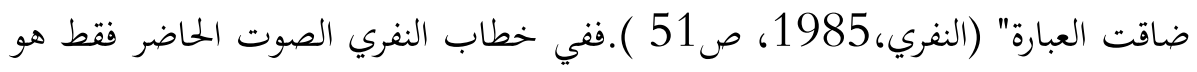

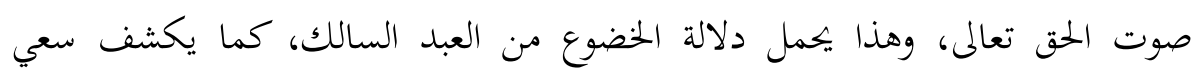

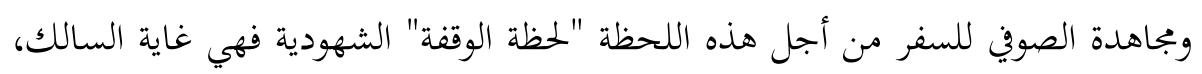

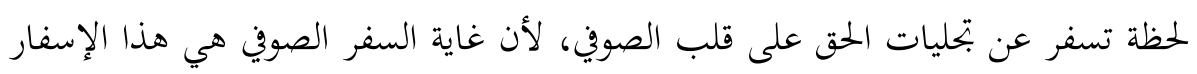
والكشف والتجلي.

وبالتالي فبنية النص النفري في الوقفة والمخاطبة بتسد لحظة التجلي بما هي تلقي

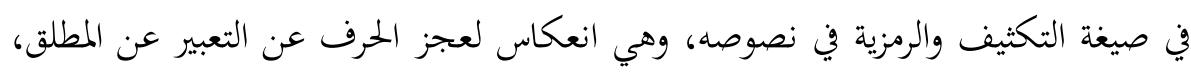
وهذا التكثيف يجعل الكلمة في مقام الإشارة بوصفها برزخاً بين الإخفاء والإظهار

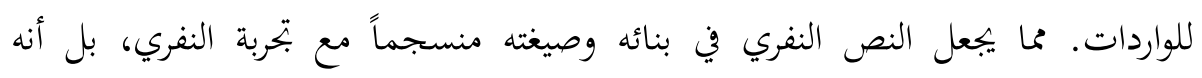

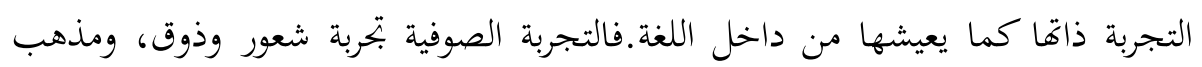

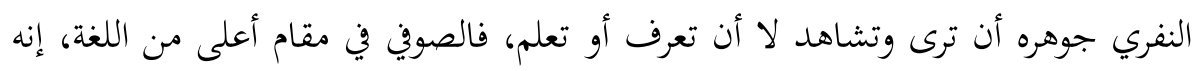

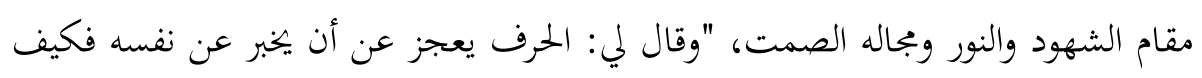

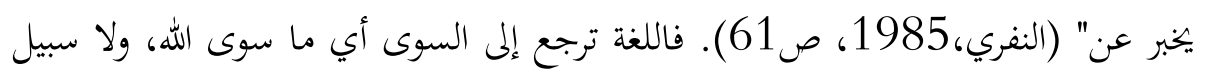

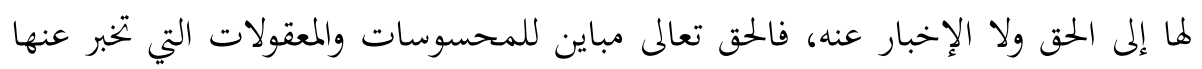

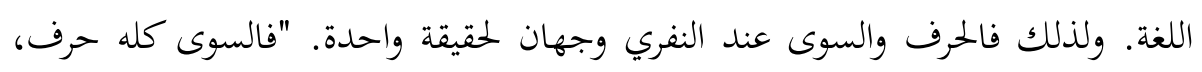

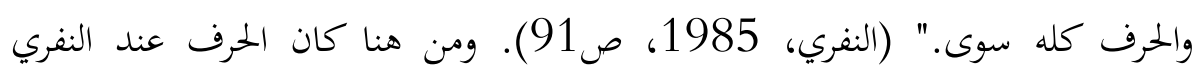

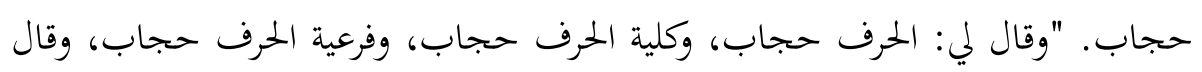

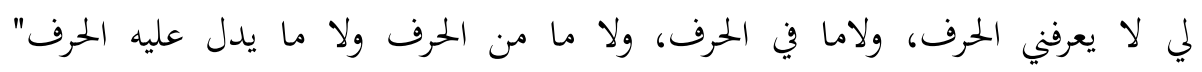

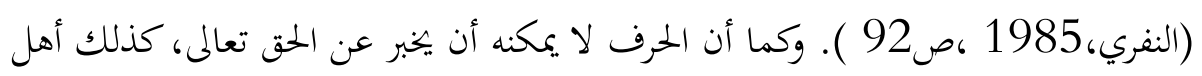

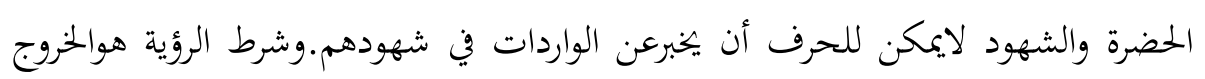


من اللغة والأشياء كلها. "وقال لي لاتقف في رؤيتي حتى تخرج من الحرف والمحروف" النا

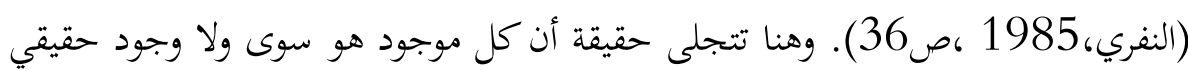

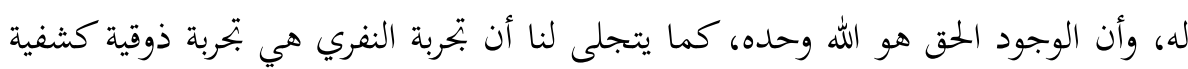

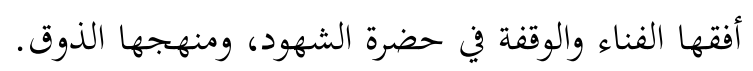
4. الوقفة: الفناء عن إرادة السوي..شهودالأحدية

يأتي أسلوب النفري متفرداً ثرياً بالدلالات العالية علو التجربة في سموها وروحانيتها

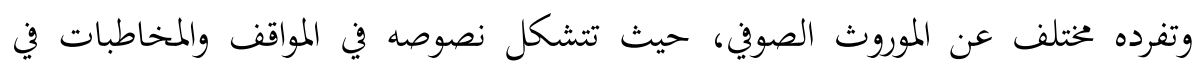

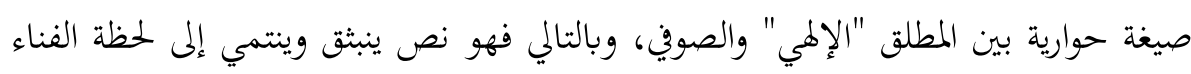

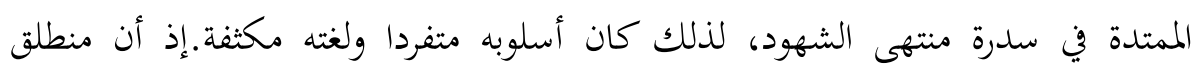

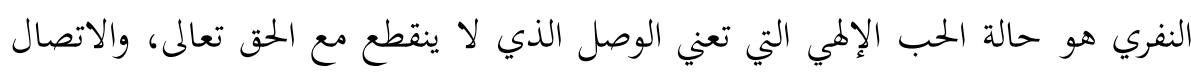

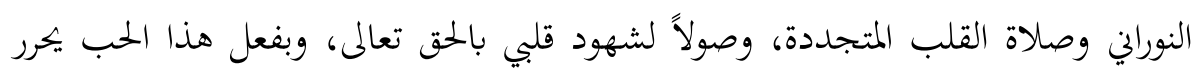

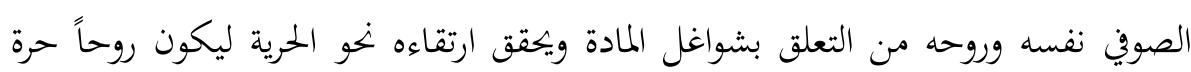

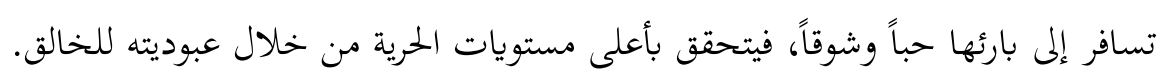
فقطع التعلق بالعالم المادي أو السوى أو الغيرية هو أساس حرية الصوفي، ودعامة

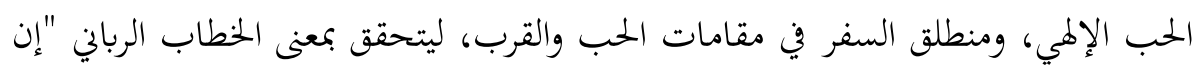

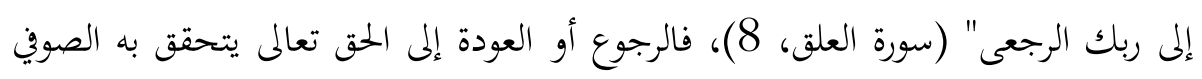

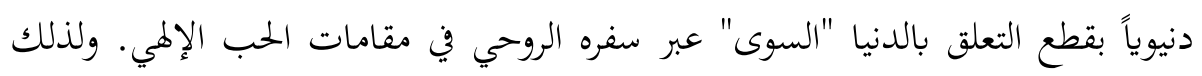

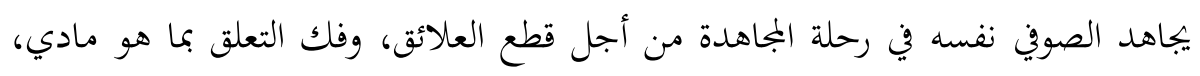

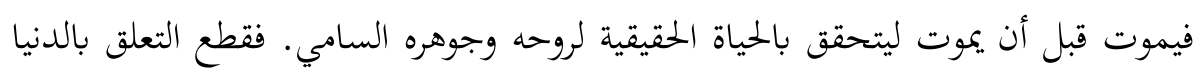

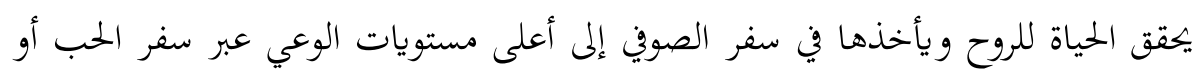

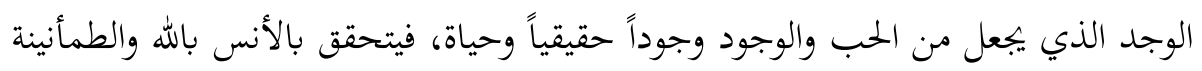
والسكينة للروح. 
فالحب للحق عند الصوفي يفضي إلى الكشف والتجلي. "يا عبد من رآني عرفني

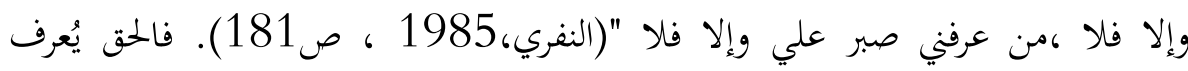
بشهود القلب، والمحسوسات حجاب يمول دون عروج العبد بروحه إلى مقامها الأعلى، ولذلك يشير النفري إلى حجاب المشاغل الدنيوية الحسية في قوله: "يا عبد إذا لم ترني تخطَُّككَ كل ما ترى" (النفري، 1985 ،ص181). فالمشاغل الدنيوية تتجاذب الإنسان

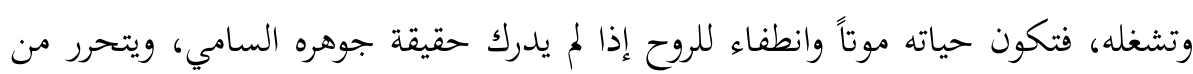
تعلقه بما هو مادي ويفنى عنه، فيرى الله في كل شيء، فإذا لم يرى الله كانت أفعاله بلا روح ولا جدوى. "يا عبد من لم يرني فلا علمه نفع ولا جهله ارتفع" (النفري، 1985، ماكي،

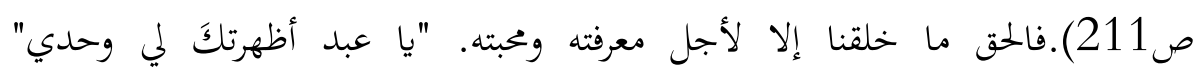

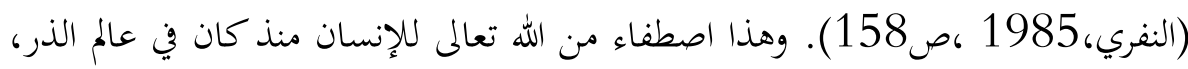
ومن هنا يؤكد النفري على العلاقة الحميمة الوثيقة بين العبد وربه، ومحبة الله السابقة على محبة عبده له، وأن مولاه هو الذي أراده قبل أن يريد هو. "يا عبد أثنيتُ عليكَ قبل

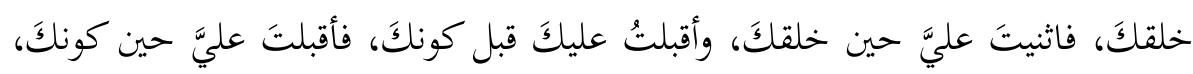
فكن لي بما كان منّي" (النفري، 1985، 178). فما خُلق الإنسان ليكون في حال الحجاب، بل ليكون في مقام القرب والحضرة والأنس بالحق تعالى، ومن هنا كان تأكيد

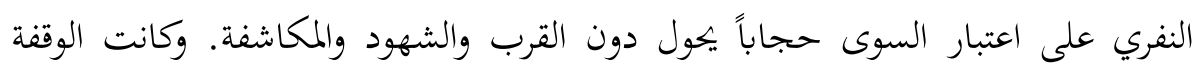

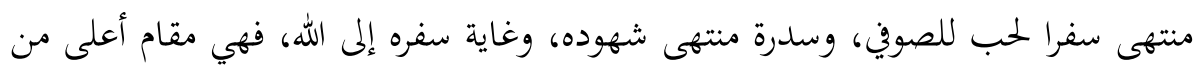

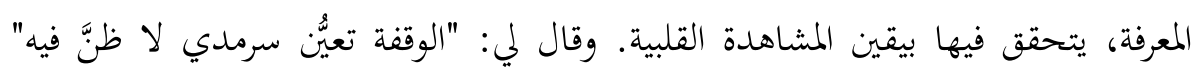
(النفري، 1985 ،ص15)، فهي شهود العارف في الحضرة الإلهية. "وقال لي: والواقف يُخبر

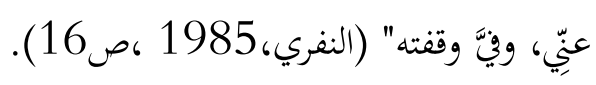

ففي الوقفة حيث تتلاشى هوية العارف الذاتية، وتنمحي عنده كل غيرية، يفنى كل

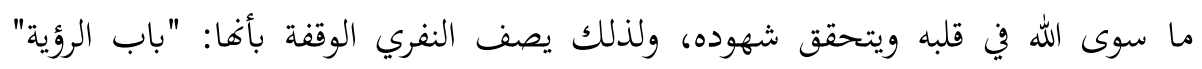
(النفري، 1985 ،ص18). فهي غاية الصوفي حيث يتحقق بالشهود في الحضرة الإلهية، 
فالوقفة للصوي تنفتح على الحضرة، التي تنفتح بدورها على اللحظة الصوفية وأفق الديمومة، حيث لا شيء سوى الله، ويصبح قلب الصوفي مرآة للتجليات الإلهية. ومن هنا يرى

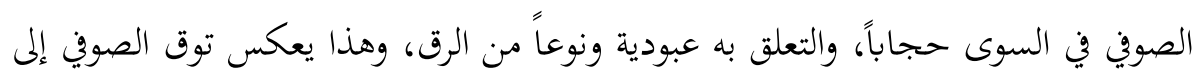
بحاوز المادي ونزوعه إلى الحرية، حيث تسمو الروح، ويتجاوز التضاد بين المادي والروحي.

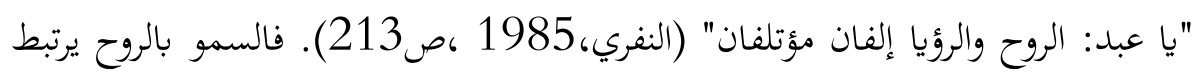
بالوقفة والرؤيا، والرؤيا بدورها ترتبط بالحضور والوصل وبتحاوز الغيبة أي السوى، فالغيبة حجاب الصوفي، بل أن النفري يصفها بأها سجن المؤمن، "وقال لي: إن رأيت غيري لم ترني" (النفري،1985 ،ص232 ) ). فكل ما هو سوى يعتبره النفري حجاباً يحول دون

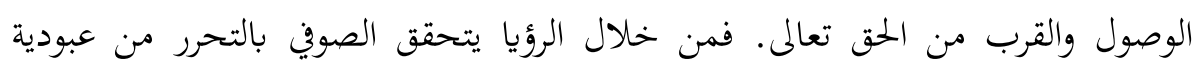

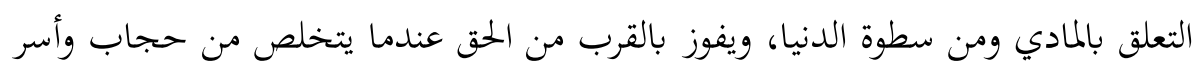
السوى. "والكون كله سواي" (النفري، 1985 ،ص22 ). ويمكن القول أن النفري يقوم تصوفه على الفناء عن شهود السوى، ويتأسس عنده على فناء الصوفي عن إرادته وأفعاله، وبقائه بأفعال الله وإرادته ، فيفنى الصوفي عن رؤية أفعال، كما يقوم تصوفه أيضا على فناء الصوفي عن شهود السوى أو الأغيار وبقائه بالله وحده. فلا يتعلق الصوفي السالك إلا بالله

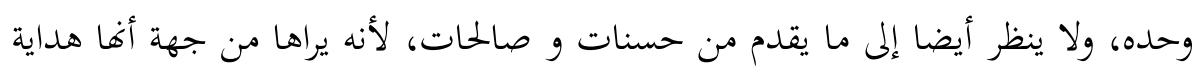
وإلهام من الله تعالى لعبده، فيحضر قلبه مع الله وحده. وفي فناء العبد عن شهود السوى يبقى بالحق تعالى ويغنى عن إنيته وعن كل شيء فهي تصير محوا عنده. وحال الفناء عن شهود السوى باعتباره أعلى درجات الفناء يسميه

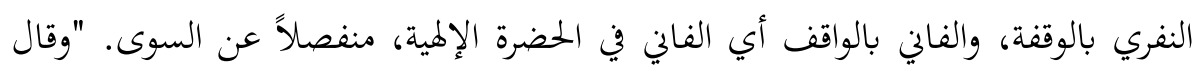
لي ليس في الوقفة ثبت ولا قول ولا فعل ولا علم ولا جهل" (النفري، 1985 ،ص24 لإن ). ولأن الوقفة تمحو الصور وفيها تفنى الرسوم، فلا يكون فيها قول ولا فعل ولا علوم، لأن كل

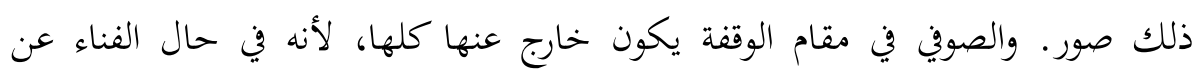
السوي، حيث يكون الحق تعالى سمع العبد وبصره.فالصوفي الفاني لا يشهد وجوداً غير الله 
وحده، والسوى عنده يكون هو العدم. "أوقفني في الموت، فرأيت كل شيء لا يقدر على شيء، ورأيت الملك غروراً، ورأيت الملكوت خداعاً، فما نفعني إلا رحمة ربي" (النفري، 1985 ،ص35). ويعني النفري بالموت هنا أي فقده إنية وجوده في حال شهوده الفناء، فيفنى إحساسه بإنية وجوده في وجود الله تعالى، ويفنى المحب في ذات المحبوب، والشاهد في المشهود، ولا يبقى إلا المحبوب المشهود، لأن الفاني في حضرة مشهوده يرى

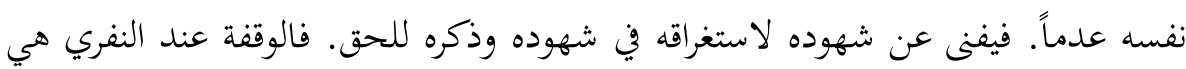
قطع تعلق الصويي بالسوى وصولاً إلى إماتة الصوفي عن السوى، وفناؤه في الله تعالى وبقاؤه به، وفناؤه هنا محو في حضور مشهوده الحق تعالى.ففي حضرة الذات الأحدية، لا يشهد الصوفي إلا الأحدية بفنائه عن نفسه وعن الوجود. ولا يرى في الوجود إلا الله تعالى، وهذا لها هو حال الفناء في التوحيد عند النفري، حيث لا يشهد الصوفي إلا الله، ويضمحل احساسه بالوجود وبذاته، فيفنى عن الكون بالخالق أو المكِّون، فيبقى الله تعالى في شهوده لئه وتفنى الموجودات. حيث لا مشهود إلا الله، ولا موجود إلا الله تعالى، وهذا جوهر التوحيد، لئل

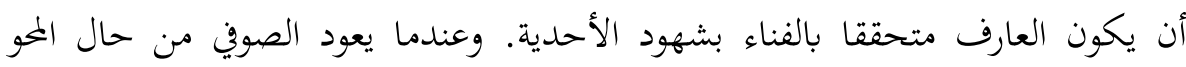
والجمع في فنائه إلى حال الصحو والفرق، فهو يشهد الكائنات والموجودات مع شهوده لأحادية الحق تعالى، أي أنه يشاهد أحادية الله في كل الموجودات.

فالنفري ينطلق من مبدأ الثنزيه، ويثبت الإثنينية بين الله والعالم، ولا يقول باتحاد أو

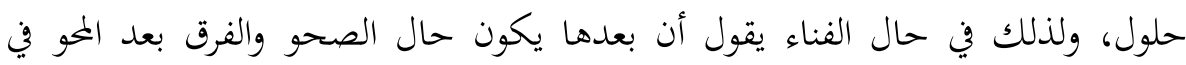
الفناء الشهودي. ومن منطلق التنزيه أيضا لا يقول بأن الواقف عرف الحق تعالى. "وقال لي ما عرفني شيء، فإن كاد أن يعرفني فالواقف" (النفري، 1985 ،صرئ28). فالواقف يظل في

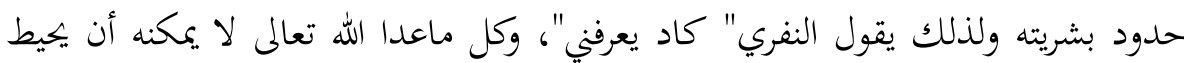
بالله كحقيقة مطلقة عليا، والذات الإلهية حقيقة لا تدركها العقول، ولا تشاهدها الأبصار. وبالتالي فالواقف مهما تحقق بسمو الروح، والتجليات لكنه لا يخرج عن بشريته. "وقال لي

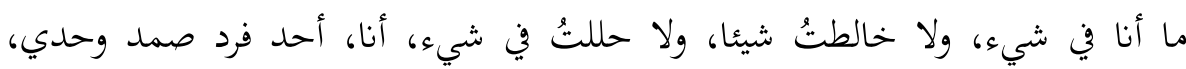


وحدي أظهرتُ ولا مُظهِهر إلا أنا" (النفري،1985 ،ص83). والنفري يؤكد في خطابه

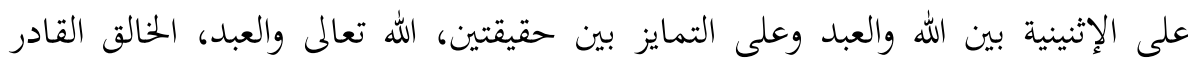

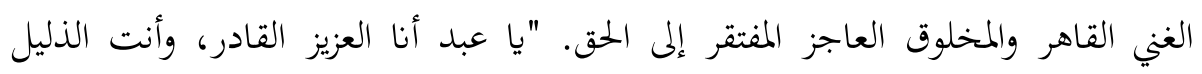

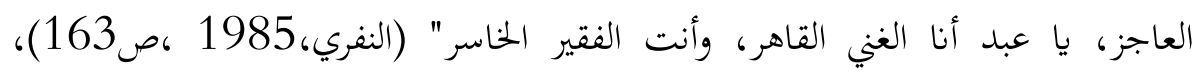

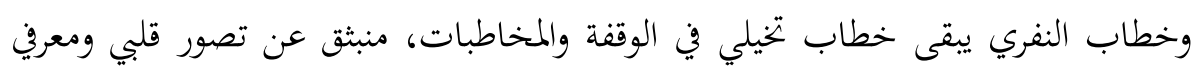
لمستوى أوحال من حالات السفر الروحي، والفناء الشهودي.

إن وحدة الشهود عند النفري بأن لا تشهد سوى الله تعالى تتأسس على التنزيه

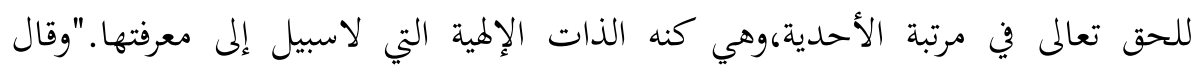

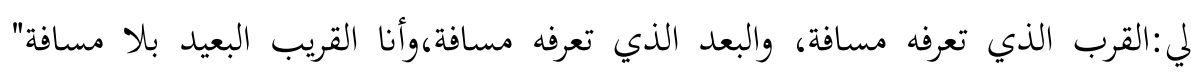

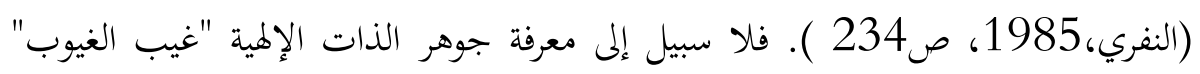

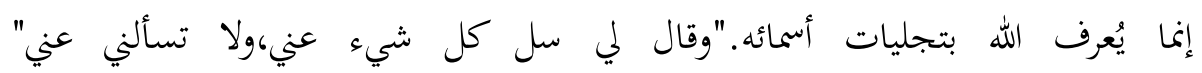

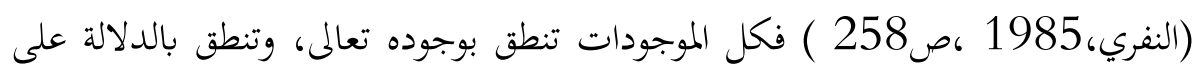

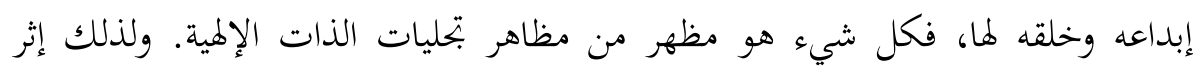

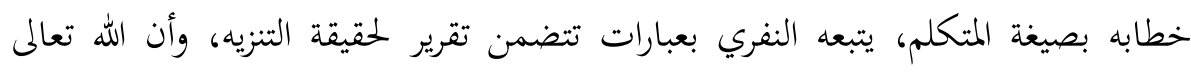

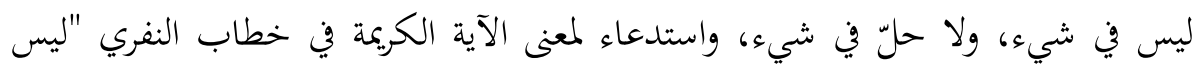

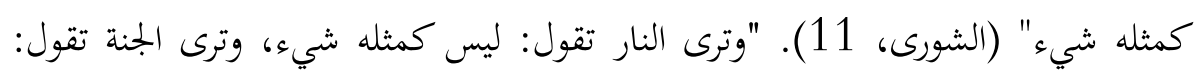

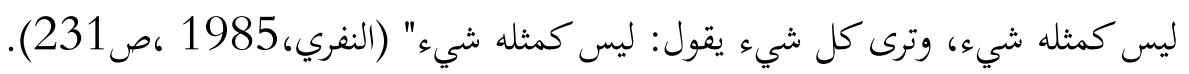

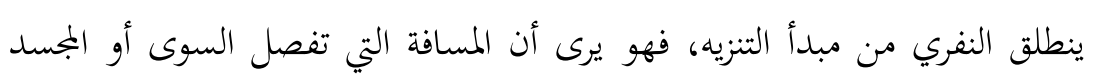

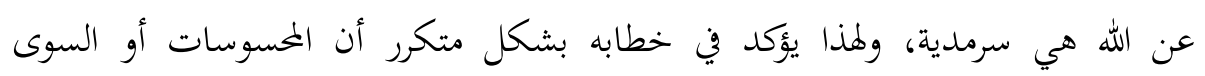

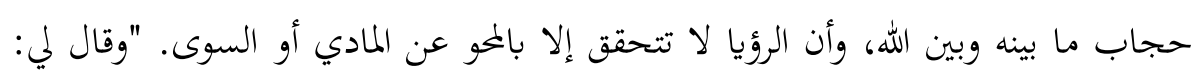

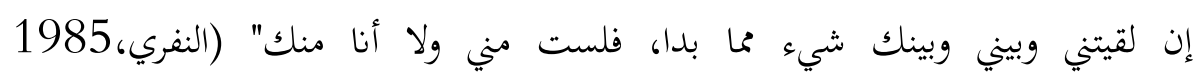


،ص211). أي إذا بقي فيك شيء من تعلق بالسوى فلن تتحقق بالوقفة ولا بالشهود،

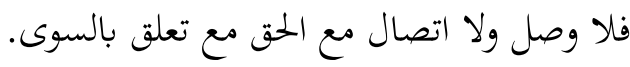

فالشهود والسوى لا يلتقيان، كما أن عبودية المادة وسمو الروح ونزوعها إلى الحق تعالى لا يلتقيان. "يا عبد من صبر عن سواي أبصر نعمتي، وإلا فلا" (النفري، 1985

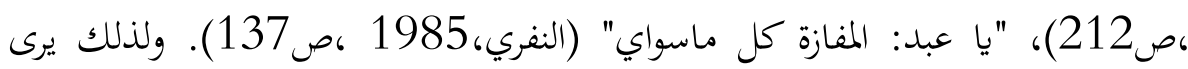
النفري في السوى والتعلق به مفازة وتيهاً، من تركه فاز بالوصول، ومن اغتنى بالله وحده فاز و وصل، ومن اغتنى بما سوى الله تاه وافتقر .ويمكن القول أن لحظة النفري الصوفية "الشهودية" تتجلى عبر ومضات أو شذرات مكثفة كأفق مفتوح على معان ودلالات متجددة، ومن خلال خصوصية بنائه اللغوي في مساقاته التعبيرية، ويتضح أن للخظته التعبيرية تأتي من داخل لحظته الصوفية الشهودية، ومكابدة في سفر المقامات، لكن النفري يظل يرى بأها لحظة وتجربة تتعالى على اللغة والحرف الذي لا يتسع لتجليات أنوارها و

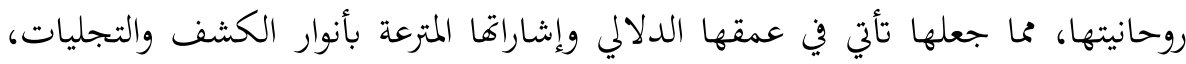
تضمر أكثر مما تفصح، وتستعصي على الشرح والكشف، لمحدودية اللغة أمام اتساع التجربة.

\section{5ستويات الإتصال عند النفري:-}

يبني النفري تصوره لمستويات الاتصال بالحقيقة المطلقة، ويذهب أها ثلاثة

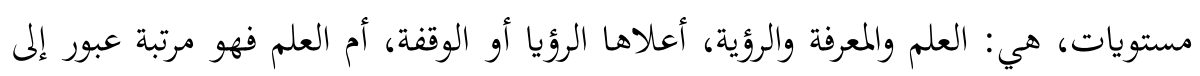

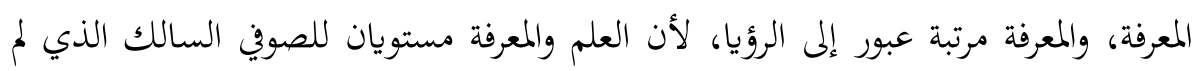

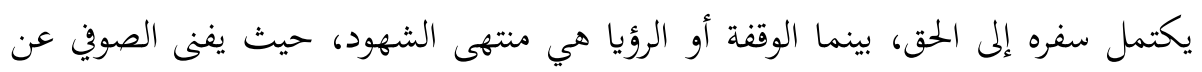

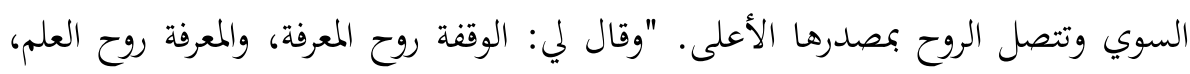

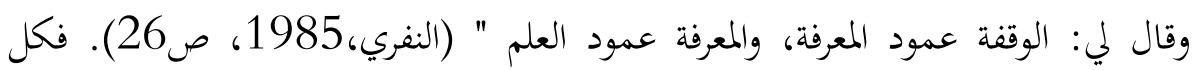
مرتبة في سفر السالك هي تمهيد لما بعدها، وكل مستوى له اتصال بالآخر، "وقال لي: كل 
واقف عارف، وما كل عارف واقف" (النفري، 1985 ،ص29). فالوقفة حضرة وشهود تتعالى على البعد والمكان والزمان. "وقال لي: العلم حجابي، والمعرفة خطابي، والوقفة

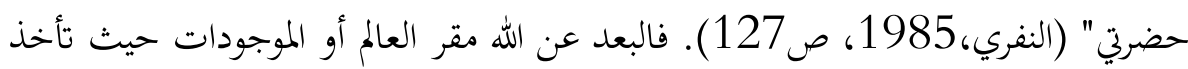
المخلوق وتدله على الخالق تعالى، والقرب من الله مقر ومقام العارف، فالمعرفة استبصار من خلال حدسه، أما الواقف فمقره حضرة الله، فهي مقام اليقين ومنتهى الشهود، فالوقفة رؤية بالبصيرة. فالرؤية عند النفري هي المعرفة الكاملة، التي يعتبرها أعلى مستوى للاتصال

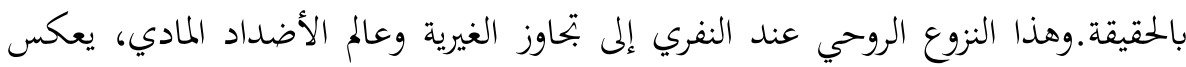
توقاً روحياً لا تشبعه المادة، لأنه توق إلى الأسمى، لذلك فهو يبتغي بتحاوز كل علم علم ومعرفة

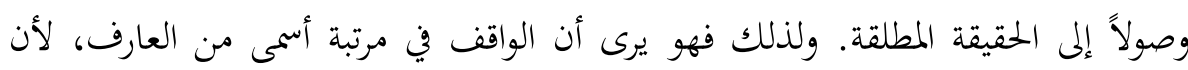
الواقف متصل بالحقيقة العليا، الحق تعالى، فالواقف الموصول بالحق تنفتح الوقفة عنده على يلى الرؤيا أو الحضرة - الشهود- "وقال لي: يا عبد من رآني عرفني، وإلا فلا" (النفري، 1985 ،ص36). وبما أن الوقفة تتحقق للصوفي بانعتاقه من السوى، أو التعلق بالمشاغل الدنيوية ونس وسطوة المادي، لذلك فالوقفة للصوفي هي أفق الحرية، واللحظة السرمدية في قلب الصوفي، حيث ينمحي عنده الزمان والمكان. "وقال لي: العالم في الرق، والواقف حر" (النفري،

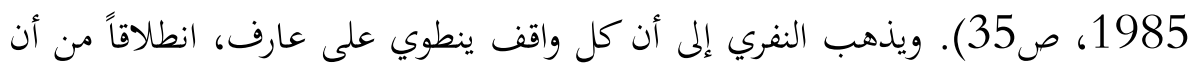
التجربة الذوقية في جوهرها ومقاماتا ماهي إلا سفر متصل لتحقيق القرب. ومن هنا كان

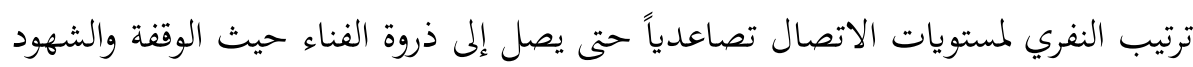

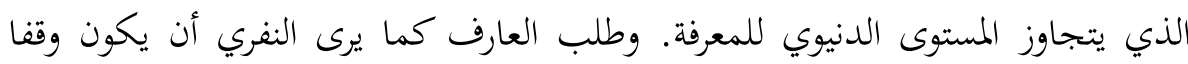

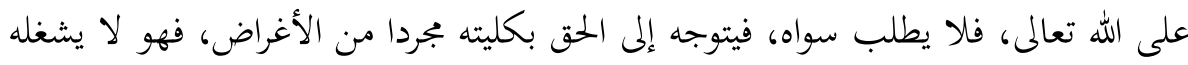
إلا الله، والقرب منه، والبقاء به، والإعراض عن كل ما سواه.فالعلم كما يذهب النفري إله حدوده عند إدراك الجزئيات والأشياء وقوانينها وهو يدلنا على الخالق من خلال البحرئ البحث في الكون والموجودات، فالحق تعالى يظهر في المظاهر دون أن تحصره ويتجلى بصفاته وأسمائه اللامتناهية، وهذا مستوى ودرجة من درجات الاتصال بالحق الكلي، لكنه مرتبة عبور. 
"وقال لي: أنا القريب الذي لا يحسه العلم، وأنا البعيد الطي لا يدركه العلم" (النفري،1985، ص727). ويفضي بنا نحو مستوى ومرحلة أعلى هي المعرفة التي تبحث في الكليات، وتأخذنا إلى الحقائق الكلية، فهي كما يرى النفري مقام أسمى من العلم، ثم

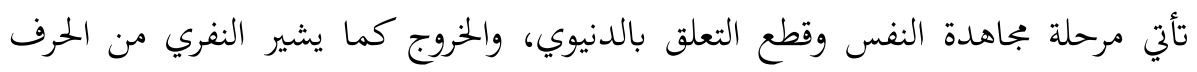

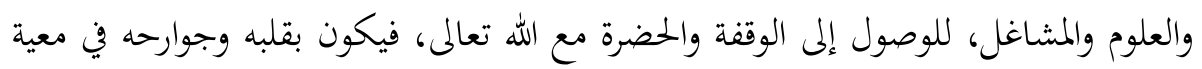

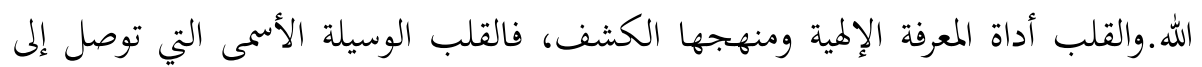
الوقفة. "يا عبد سد باب قلبك الذي يدخل منه سواي، لأن قلبك بيتي، يا عبد بيتك مني

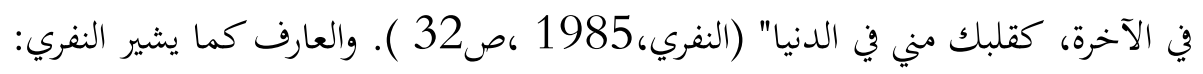
"فنى عن بعض رسومه، وبقي بالبعض الآخر" (النفري، 1985، صني، (34)، فهو متعلق بالحق لما وصل إليه في شهوده ومحوه، ومع الخلق في صحوه لما بقي فيه من رسمه، فالصوفي يكون بربه عندما يتجاوز السوى، ويفنى السوى عنده. 6. هاجس القرب وتجليات المعنى عند النفري:-

يسيطر قلق المسافة أو هاجس القرب على خطاب النفري، فيتجلى لنا خطاباً

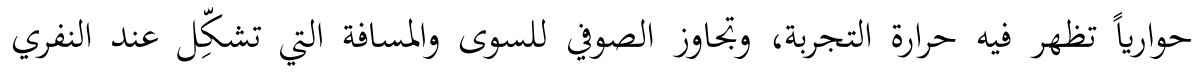
هاجساً، وباعثاً على بتاوز الرغبات، واستكشاف واستبصار داخل الذات وجوهرها النوراني

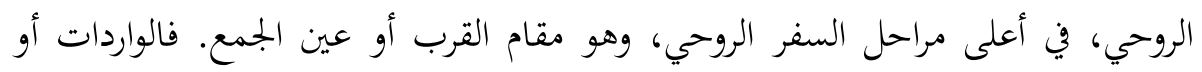

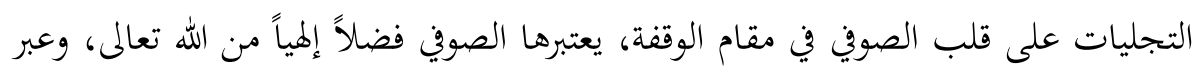
الممارسة الخطابية للتجربة، يحاول النفري استكناه بحليات المعنى، ليتحقق بفهم الذات

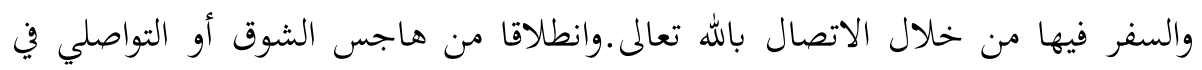
عمق الذات الصوفية، يمارس النفري الكتابة من خلال استحضاره للمعنى اللغوي للكتابة

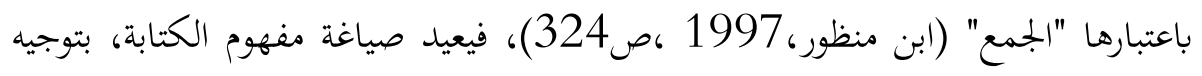
الجمع بتحاه بتربته الذوقية بما تنطوي عليه من دلالات ومعاني التجلي والشهود، ومن هنا 
تكتسب الكتابة أفقاً متسعاً ولا تكون محدودة بقوالب جامدة، فيكتسي الجمع والتوحد معنى خاصاً في بعده الصوفي الذوقي، انطلاقاً من هاجس الصوفية والنفري الأساسي، وهو هاجس المسافة، والتحقق بالقرب عبر تجاوز هذه المسافة من خلال تجربتهم الذوقية، فالسالك غايته من سفره الروحي تحقق القرب وعلى ذلك تصبح الكتابة اقتراباً بتوجهها للغة، وانضمام المعنى للمعنى في نسيج خطاب النفري، ويفترق من جهة أخرى لاختلاف

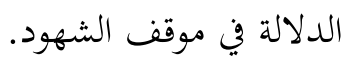

وبالتالي ينقل النفري الضم إلى سياق التجربة الصوفية، ويبعلها تتضمن دلالة ترتبط

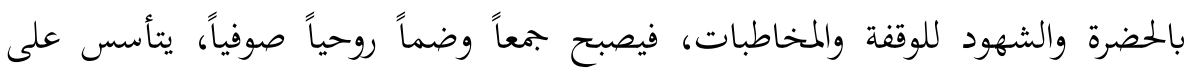
التجاوز للمعنى المألوف الذي يصبح وكأنه سوى يتم بتاوزه، كما يتأسس هذا الجمع ولئ الصوفي على تلاشي المسافة شعورياً بين السالك ومحبوبه، هو ذاته التلاشي الذي يعيشه الصوفي في سفره في معراجه الروحي. فهو سفر يتأسس على التوق إلى القرب الذي يقوم على التحلي، بينما يقوم البعد على التخلي، مما يجعل الصوفي في تحول مستمر، ويتجلى ذلك في كتابة التجربة باعتبارها مقاما في سفر الصوفي، حيث كان هاجس الكتابة في أفق بقدي الرؤيا والشهود هاجس النفري، كما هو هاجس القرب في سفره الروحي، ومن هناك كانت الوشائج بينهما لا تنفصل، لذلك نجد النفري يعمل على تأصيل الكتابة في تجربته الذوقية،

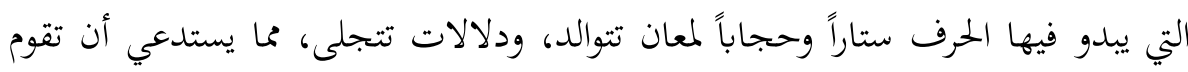

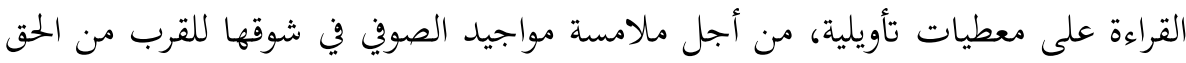
تعالى "المجبوب".فالوقفة لا تعني التوقف، وإنما هي وصل القلب الصوفي واتصاله في لحظة شهوده بالحي الذي لا يموت الله تعالى، فيراه السالك أقرب إليه من نفسه "من حبل الوريد". "وقال لي: بيتك هو طريقكَ، بيتك هو حشرك، أنظر كيف تراه كذا ترى ما سواه" (النفري، 1985 ،ص1321 ). إنه قلب المؤمن السالك، البيت الذي وسع الحق تعالى، فكان معموراً بنوره، وهو ذات القلب الذي إذا غطاه حجاب الغفلة يصير قبراً، هو الغوريات القلب فيه حشر وقيامة المؤمن، ووصله مع ربه تعالى، هو قلب المؤمن يتلألئ بأنوار التوحيد 
حباً وشوقاً لله تعالى، ومرآة التجليات في مقام القرب.ومن هنا تحلى خطاب النفري في

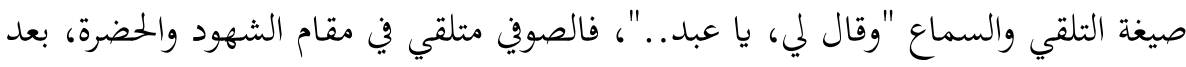
أن تحقق بإخلاء القلب عن السوى، وطهر مرآة القلب، ليكون في حال الشهود والتلقي

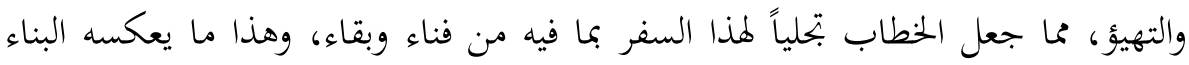

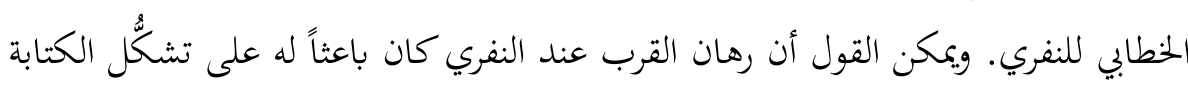

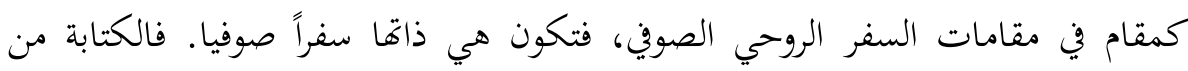

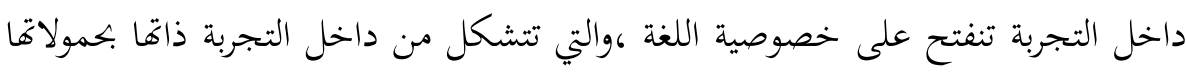

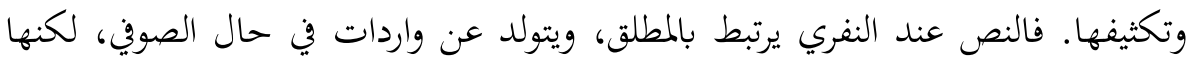

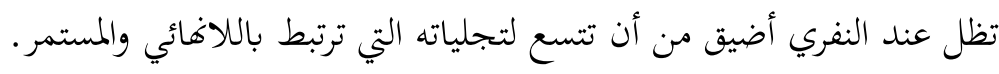
وبالتالي تتأسس الكتابة من داخل التجربة على حمولات الدلالة اللغوية في التجلي

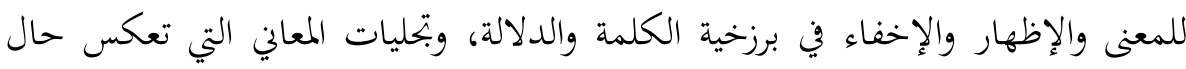

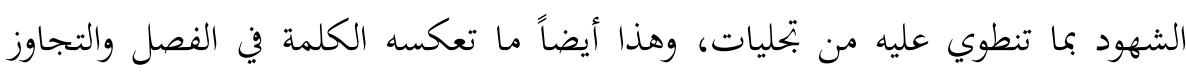

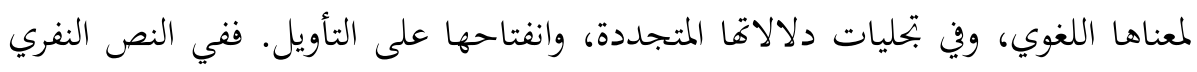

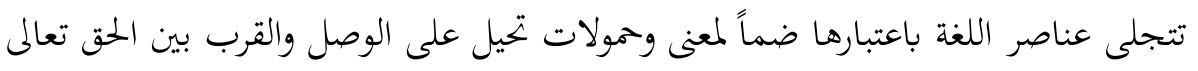

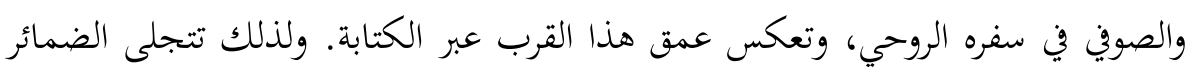
"المخاطب والمتكلم" بشكل مكثف عند النفري، وتبدو مشحونة بدلالة الشهود والتجلي عندي.

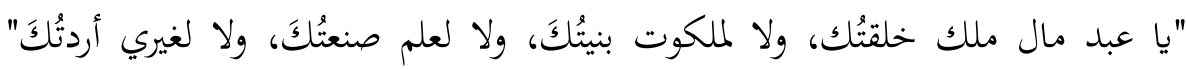

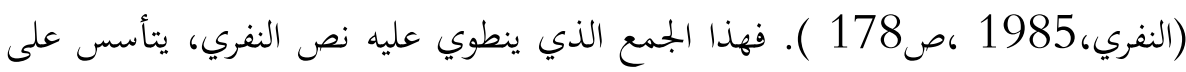

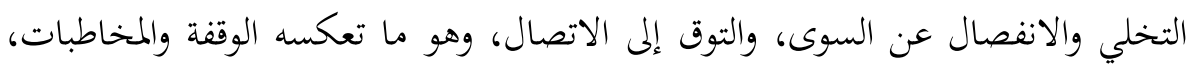

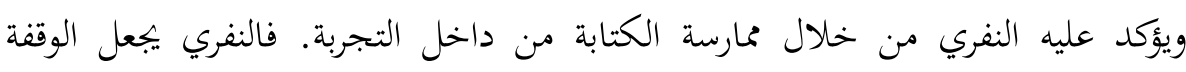

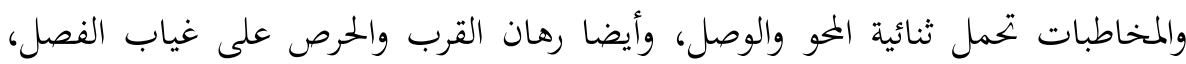

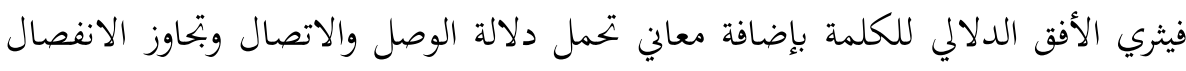

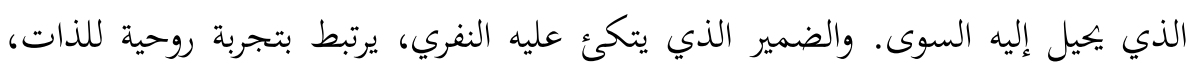


حيث تتلاشى الذات في حال فنائها، وهو ما يعكسه ضمير المتكلم والمخاطب، والذي

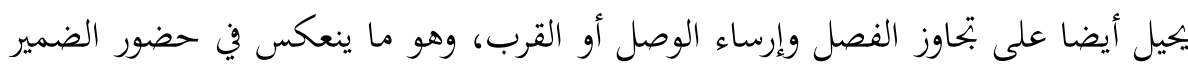

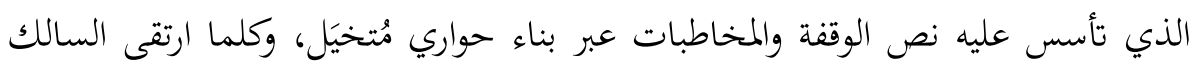

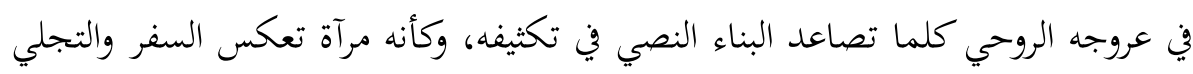

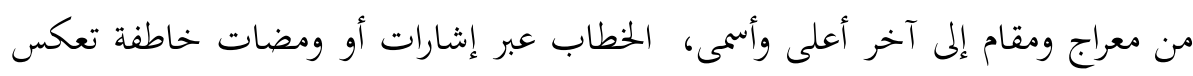

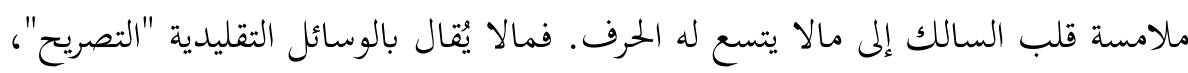

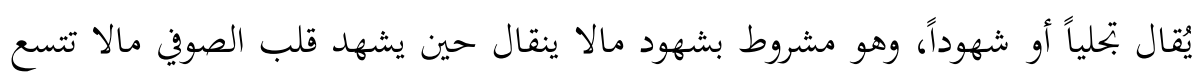

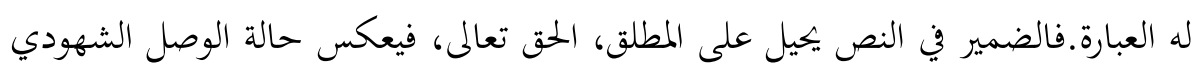

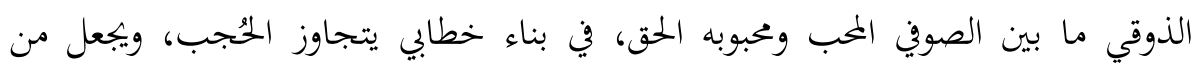

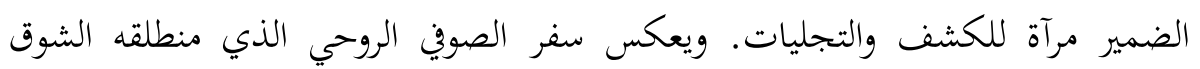

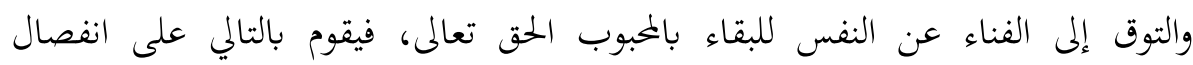
واتصال، انفصال عن السوى واتصال بالله يجعل السالك يرى نفسه بالحق، فيكون الله الله

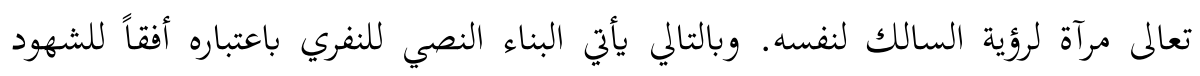

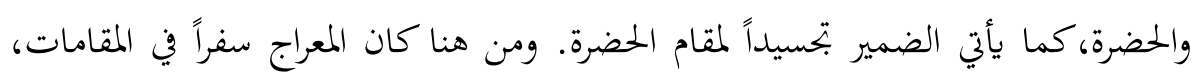

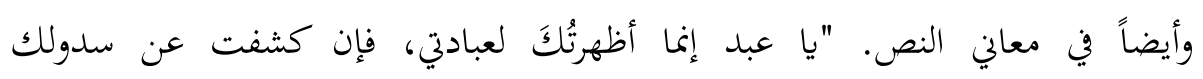

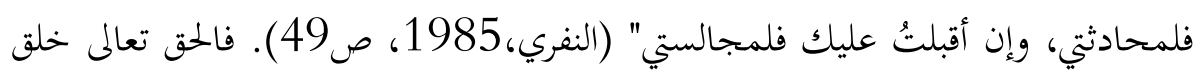

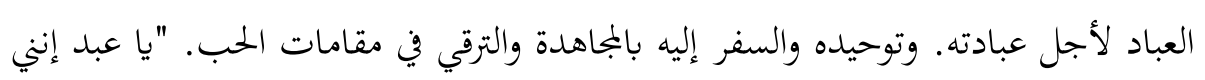

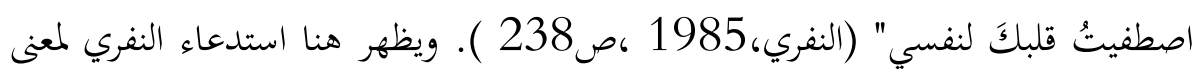

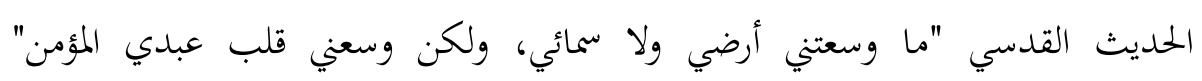

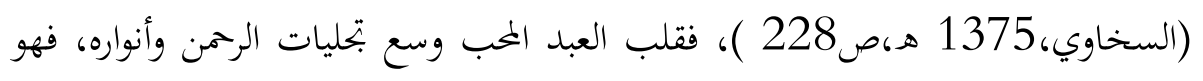

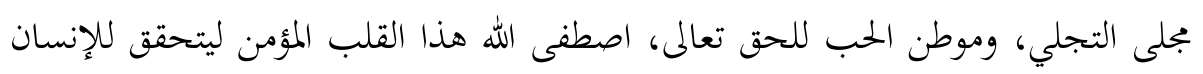

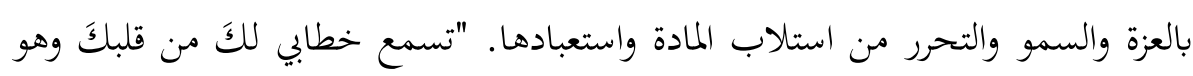

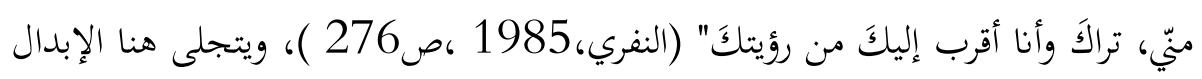


بالضمير في "تراك" فلم يقل "ترى نفسكَ"، بل ابدلها بالضمير "الكاف"، وكأن الضمير الكاف هنا يتجلى كمقام، ليسكن قلب السالك في رحمة محبوبه وخالقه. ففي مرآة قلبه يرى الحق، ولأن قرب الحق تعالى يملأ قلبه و يمتلئ به فلا يرى نفسه، لأنه لا يرى سوى

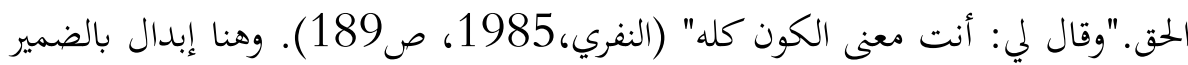
"أنت"، ولم يقل الإنسان، فضمير الخطاب "أنت" هنا يصبح مقاماً في رحاب الحق، وأفق إنق الشهود، لأن الضمير أنت في هذا السياق النصي تنطوي على معنى الحميمية القرب،

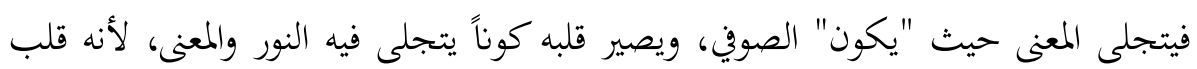

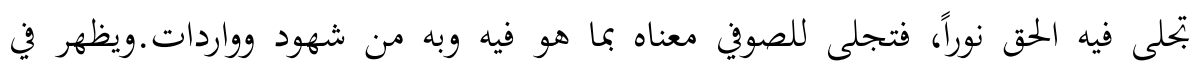
نصوص النفري أها تتقاطع مع القرآن الكريم والحديث القدسي، من خلال فاعلية الحوار المتخيَّل، وأسلوبية الخطاب، قال حنفي "والمواقف تعبر عن المقامات والأحوال جملة ، دون الثرن تفصيل لما بأسلوب شخصي بضمير المتكلم المفرد ما يدل على أها بتحارب روحية ذاتية"

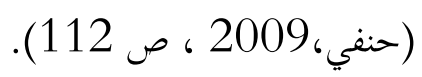

يمكن القول أن الوقفة يتجلى فيها القلب كوناً تنعكس على مرآته التجليات

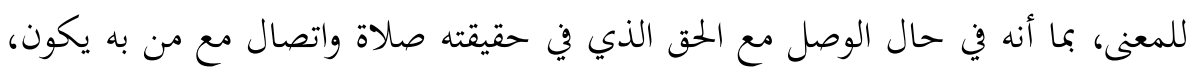
فتأتي الوقفة في معناها وبحلياتا ضداً على الثبوت والجمود الذي هو موت التئ وانطفاء، بينما القلب المؤمن هو في حال حضور مع الحضرة الإلهية، وبالتجلي المتجدد الذي به الحياة والولادات للمعنى. فالوقفة بالتالي حضور متلليء، ووصل واتصال، حيث يتوارى حجاب الغيرية والسوى والغفلة.ومن خلال الوقفة والمخاطبات يعكس النفري نصاً من داخل فئل

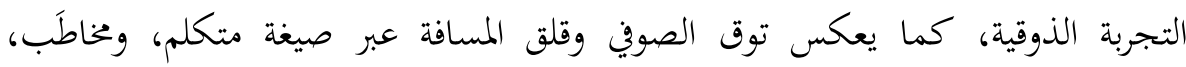
وبحليات للمعنى، ولذلك كانت المواقف بمثابة ثمرة للشهود، والوصول إلى مقام القرب، فخطاب النفري هو خطاب الوقفة والتجليات، شاهد على شهود السالك لله بيقين القلب في عروجه إلى الله. ولأن الوقفة عند النفري هي أعلى من المعرفة، لذلك يعتبر خطابه في الوقفة هو خطاب ما فوق المعرفة، وهي مرتبة للكشف تتحقق للسالك بقطع السوى. 
"وقال لي أليس إرسالي إليك العلوم من جهة قلبك، إخراجا لك من العموم إلى الخصوص،

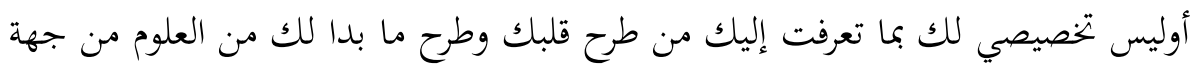

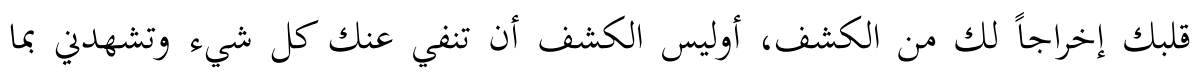

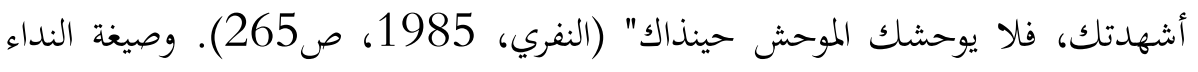

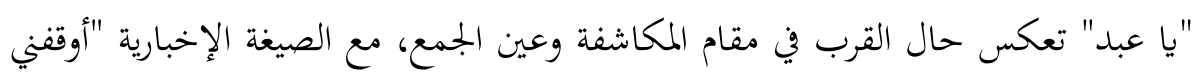

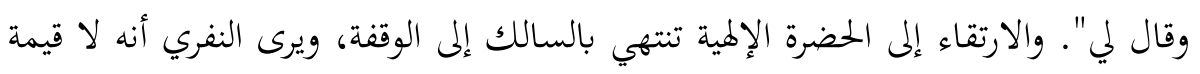

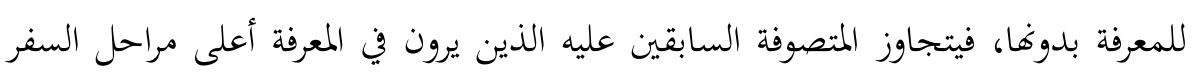

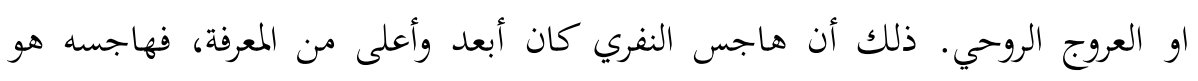

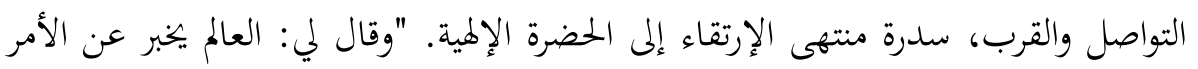

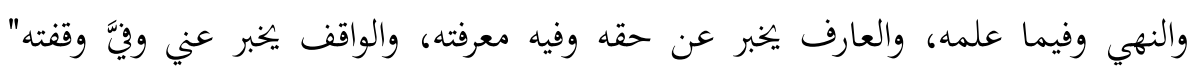

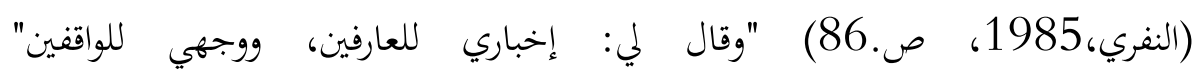

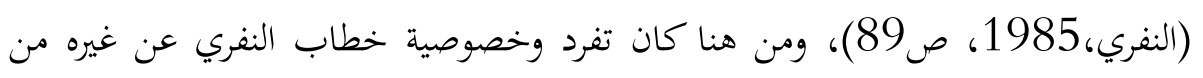

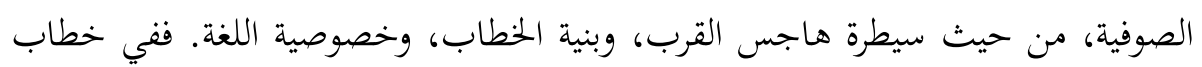

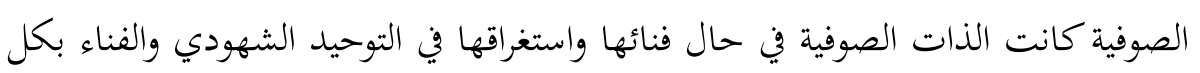

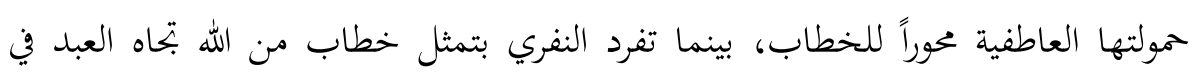

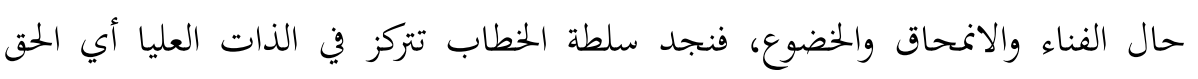

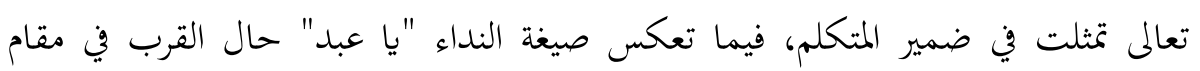

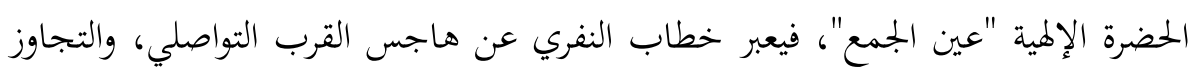

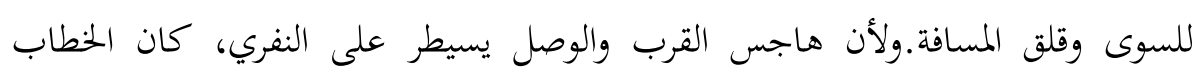

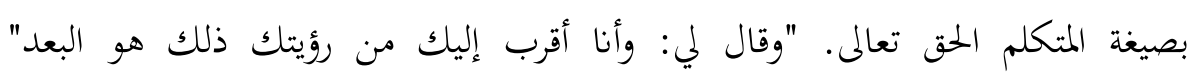

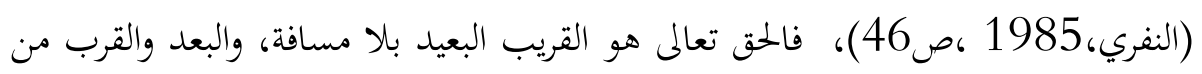

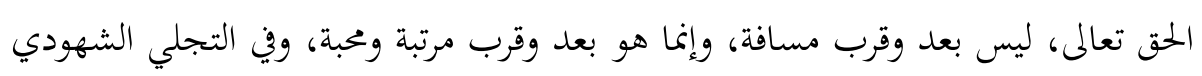

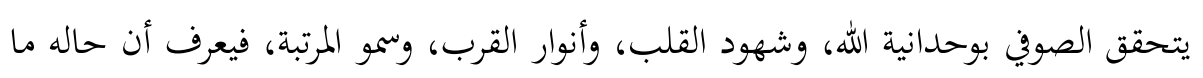


قبل وصوله لهذه المرتبة العلوية الروحية، أي ما قبل وصوله للشهود والتجلي وبحاوز الغيرية والسوى، إنما كان هو حال "البعد"، وعرف حقيقة القرب مع الله تعالى بالشهود.والمسافة

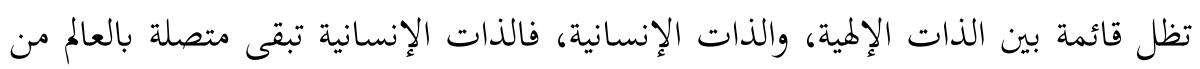

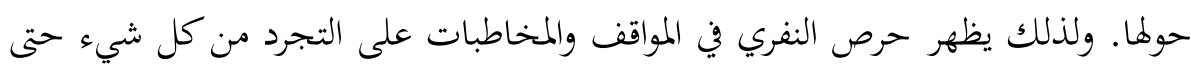
المعرفة، لتكون المخاطبة في الوقفة صيغة أخرى لتحقيق القرب والتواصل مع الله تعالى، يرى لترى

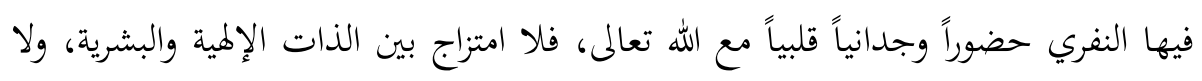

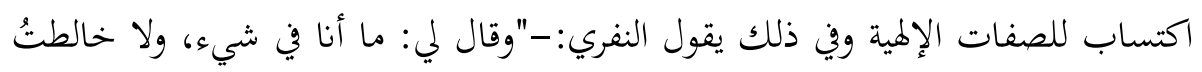

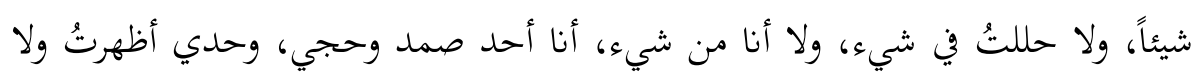

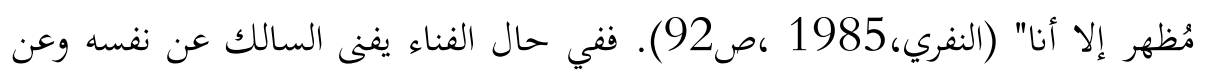

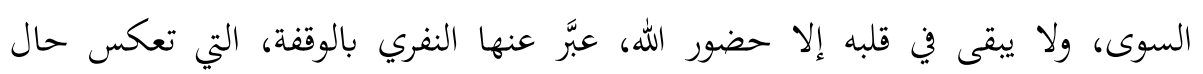

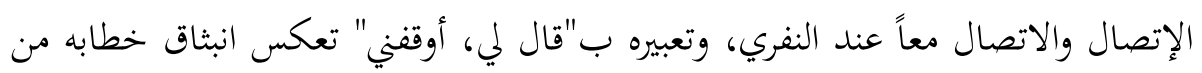

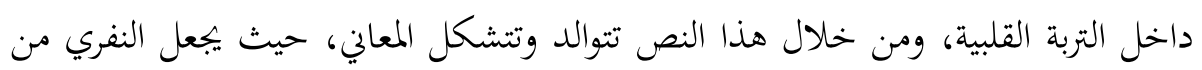
الله تعالى في نصوصه مصدراً لسلطة الخطاب، كما يجعل من السالك الصوفي متلقياً، ومن داخل هذا النسق الخطابي يأتي التواصل والتفاعل.

وتتجلى المواقف والمخاطبات من خلال ثنائية الجمل أو الوحدات في صيغة

خطابية، الجمل الشرطية. "وقال لي: لو اجتمعت القلوب بكنه بصائرها المضيئة، ما بلغت

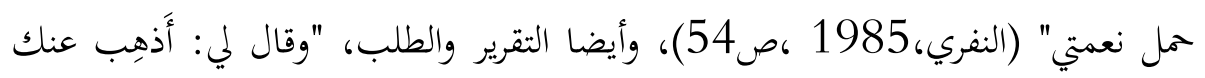

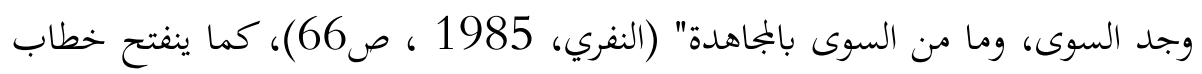

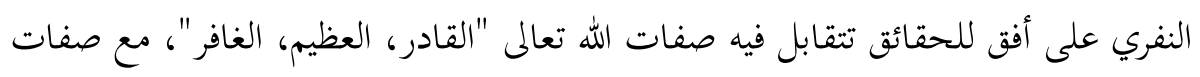

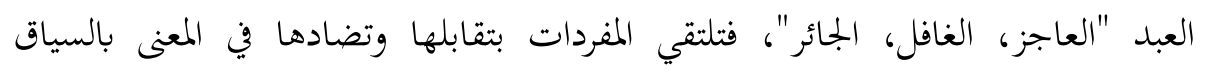

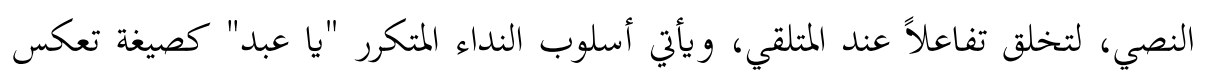

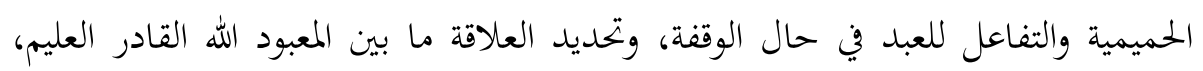

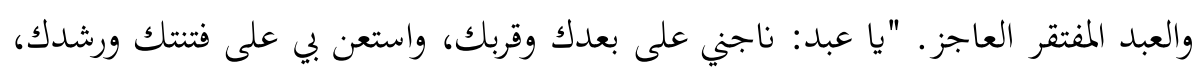


يا عبد: أنا العزيز القادر وأنت الذليل العاجز، يا عبد: أنا العليم الغافر وأنت الغافل الجائر،

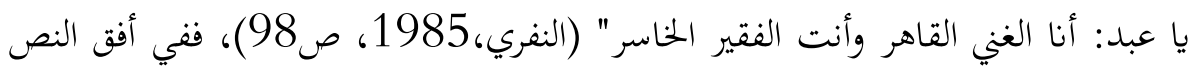

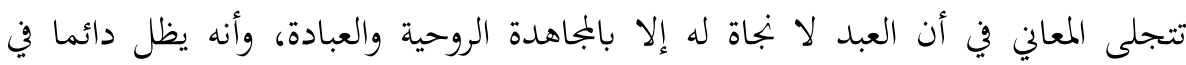
مساحة الافتقار والاحتياج إلى المعبود، والرضا بما يعطيه. وينطوي نص النفري على انفتاح لمعان جمالية ولغوية ورمزية لامتناهية في دلالاتما، عبر وحدات النص في صيغته الخطابية الطلبية، والتي تأتي كجواب لشرط، أو نداء من خلال أسلوب الأمر والنهي والاستفهام الذي يأتي محملاً بمعاني تتجاوز حدود الطلب فتئوالد المعاني والدلالات. وهذه الصور الخطابية في نصوص النفري بما تتميز به من معطيات روحية تأملية

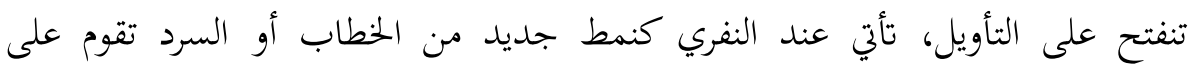
استذكار خطاب بينه وبين الله في مقام الشهود، حيث يتموضع فيها النفري في حال الشهود، أو يأتي كسارد من خلال تعبيره "أوقفني، وقال لي"، أيضا تأتي نصوص النغري كمعادل خطابي لتوق الصوفي في التحقق بالقرب والتواصل مع الله، حيث يتموضع العبد السالك في حال المتلقي، فتتجلى عبودية المؤمن، فالمؤمن لا يقف موقف الند مع الله تعالى،

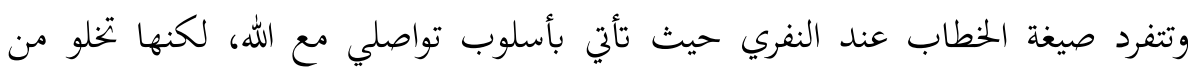

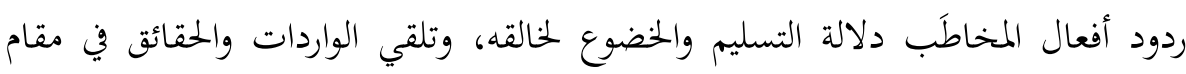
العبودية. وهذا الخطاب المتتخيَّل من النفري الذي غايته الموضوع، حيث يسند النفري الخطاب إلى الله عبر لغته المكثفة في صيغة التعظيم، ويكون النفري في موضع الاستشعار بالعبودية والإنمحاق أمام عظمة الله.ويمكن القول أن لغة النفري المتفردة في المواقف والمخاطبات هي لغة "مقام السر"، حيث تتوارى المعاني خلف حجب الرمزية والتكثيف، فهي ليست لغة البوح والتصريح، و تأتي هذه اللغة عبر صيغة خطابية، وأسلوب التقرير والطلب، والنفي والإثبات، في أفق ينفتح على الزمان والمكان، لتتجلى من مقام الكشف والتجليات، فتصبح الكلمة مجلى للمعاني المتخيلة. حيث تتفاعل الضمائر على امتداد 
النص، وينفتح فيه فعل الأمر والمضارع على ثنائيات السر والعلن، الوحدة والجمع، الخلوة والملاء، الفناء والبقاء، يعيشها الصوفي ما بين بسط وقبض، وجمع وفرق في سفره الروحي. كما تأتي ثنائية الأضداد في البناء النصي للنفري لتحيلنا على الجلي والخفي، والكثرة والوحدة في العالم عبر الأفعال والضمائر التي تنفتح على الإستمرارية وطبيعة التجليات على قلب العبد في مقام الشهود، حيث لاثبات، بل ولادات متجددة. فنصوص ولتهر النفري تعكس تجربة ذوقية شهودية تواصلية، تقوم على ثنائية الوصل والفصل، الاتصال والانفصال، الفناء والبقاء، وكأن النفري عبر نصوصه المنفتحة على التأويل بحمولتها الدلالية، ولغته الرمزية بخصوبتها وخصوصيتها، يماول الإمساك بلحظة متتدة في الزمن، لحظة التجلي الشهودية المنفلتة من اللغة والزمان، محاولاً رصدها عبر لغة لا تستوعب هذه اللحظة الإستا في اتساعها ونورانيتها.ويمكن القول أن نصوص النفري تتجلى فيها سمة بارزة هي ثنائيات

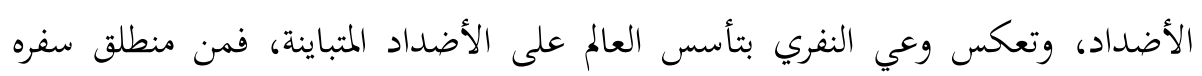

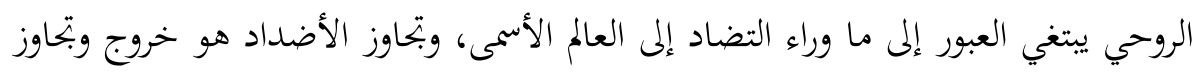

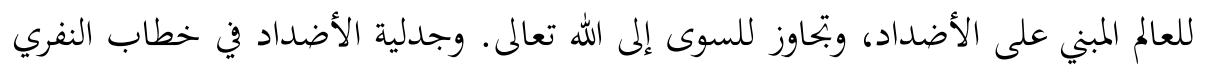

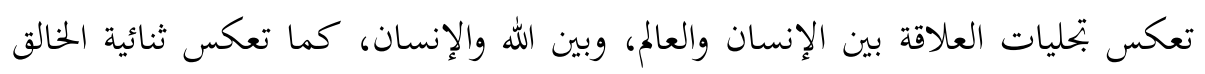

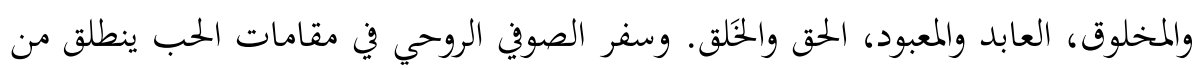

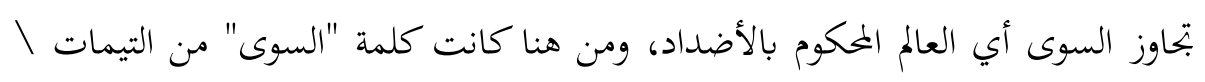
المواضيع الجوهرية في خطاب النفري، بالإضافة إلى "الوقفة، المخاطبة، الرؤيا".فكل ماعدا

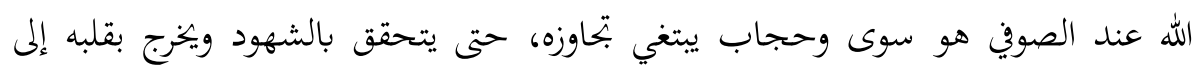
أحدية الحق تعالى، "وقال لي: أخرج من السوى تخرج من الحجاب" (النفري، 1985 ،ص118)، فشرط الإرتقاء إلى الشهود في مقامات العروج وصولاً إلى الحضرة، هو الخروج

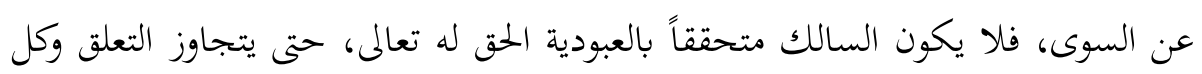

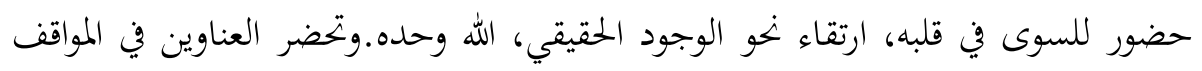
والمخاطبات "موقف القرب، موقف العز، موقف الوقفة، موقف الرحمانية..." بمثابة عتبات 
نصية تأخذنا للكشف عن المعاني الكامنة في النص، فهي بمثابة مفتاح لتأويل النص الذي تتعالق معه، ولذلك فهي تسهم في البناء النصي والدلالي، حيث تنفتح هذه العتبات النصية

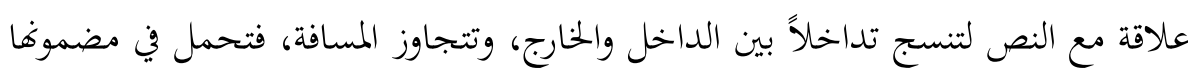

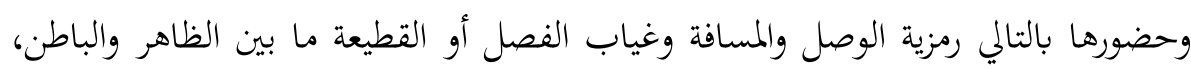
ودلالة أن الظاهر ما هو إلا تجل للباطن ،وأن سفر الصوفي هو بتل لتوقه القلبي إلى حضرة الله تعالى، وأن النص النفري ما هو إلا انعكاس لتجليات نورانية على قلبه في شهوده.

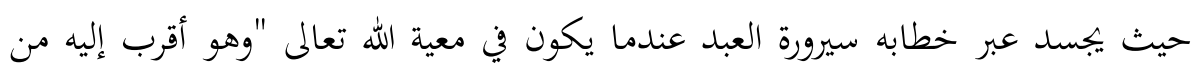
حبل الوريد"، فيعكس هذا القرب الذي يعيشه ويشعر به الصوفي حين يفنى عن السوي.ولاشك أن الابحاه التداولي يتجلى واضحاً في نصوص النفري في المخاطبات والوقفة في الحضرة الإلهية، والحديث القدسي" لا يزال عبدي يتقرب إليّ فإذا أحببته كنت سمعله الذي يسمع به وبصره، فالنفري لا يشير مباشرة إلى نص الحديث، بل يجيلنا إلى تحولات

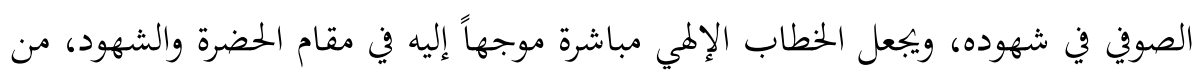
خلال الوقفة التي جعلها أفقاً للتفاعل عبر الحوارية الخطابية. "وأنا إليك أنظر، لا بين بيني وبينك، أنا أقرب إليك من كل شيء، وأنا أقرب إليك منك " (النفري، 1985،

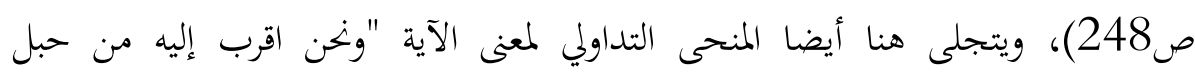

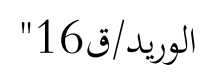

فالمواقف والمخاطبات بانفتاحها على الدلالات هي بمثابة انعكاس لصور التجليات على قلب الصوفي، ولذلك كان التنوع والثراء الدلالي مرآة تعكس صور التجليات، وإذا كان قلب الصوفي يتسع بحسب الواردات، كذلك تتعدد الدلالة داخل النص النفري لتفضي إلى تأويلية تكشف الحجب عن معان متجددة. لقد جعل النفري من الرؤيا أفقاً لا

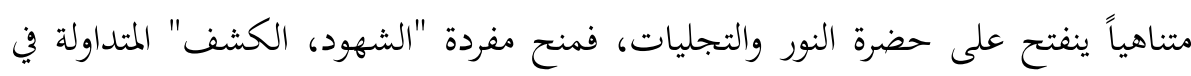
النصوص الصوفية، طاقة نور متوهجة جعلتها متجددة في معانيها ودلالاتما، عبر الخيال

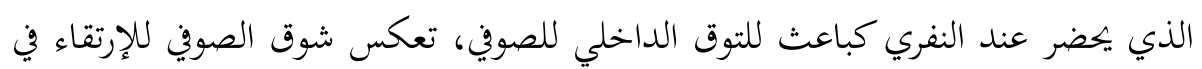


مقام الكشف والقرب، وتحاوز السوى إلى أفق أرحب تسكن إليه روحه. إن نصوص النفري

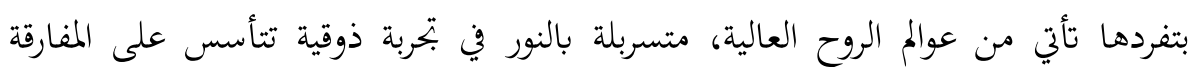

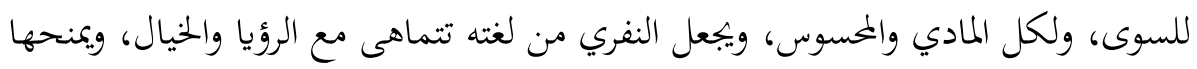

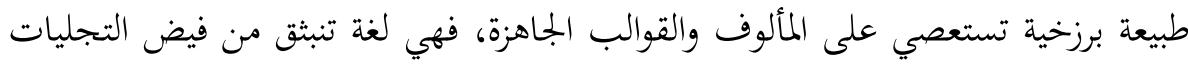
على مرآة القلب. وكأن اللغة أيضا تحقق تحررها من الاعتيادي، كما يحقق الصوفي تحره من

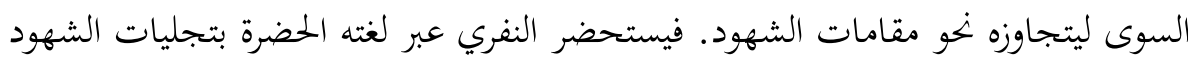

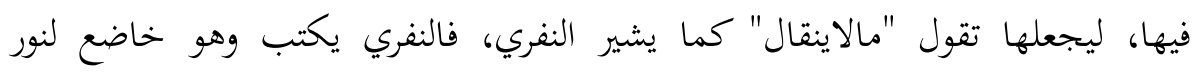

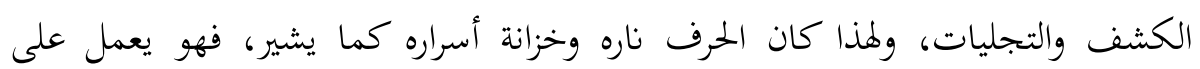
استلهام مكنونات روحه من داخل أناه المسكونة بالحب إلى الله تعالى.

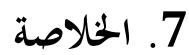

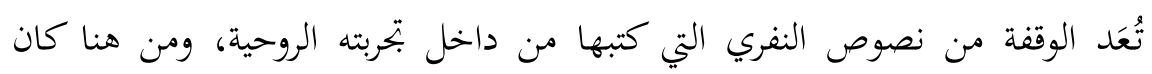

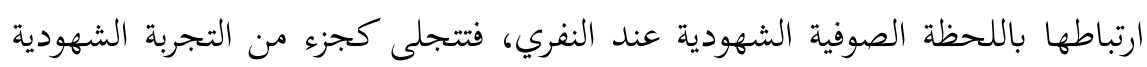

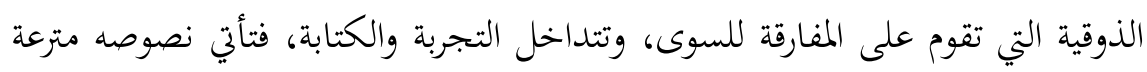

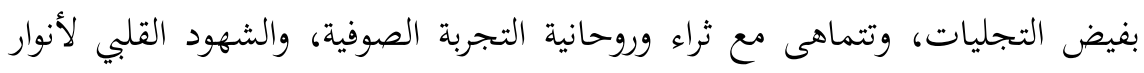

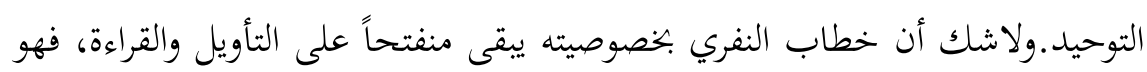

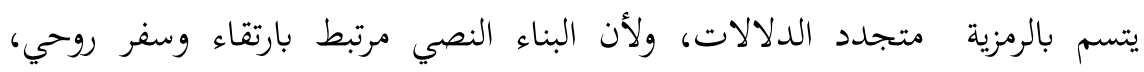

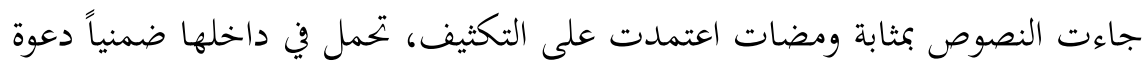

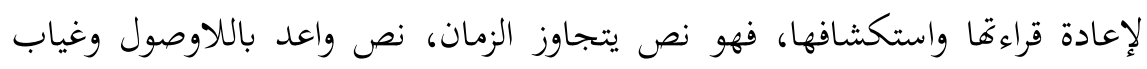
النهايات، لأنه متجدد الفيض في معانيه.

تبقى اللغة عند النفري ذلك المحدود الذي لا يمكنه أن يستوعب للظة الصوفي

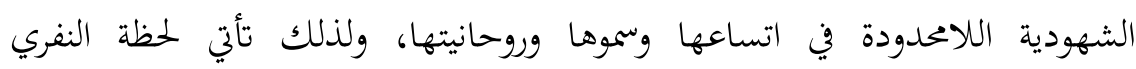
الشهودية عبر لغة لما خصوصيتها وكثافة حولتها، في مستويات للتعبير والدلالات

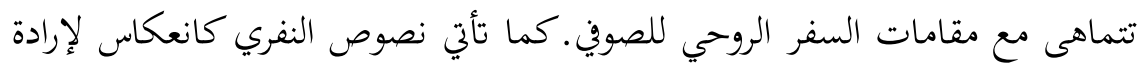


الصوفي الحرة في أسمى بتلياتا، عبره سفره الروحي، ومن داخل بتربته الشهودية، فيأخذ

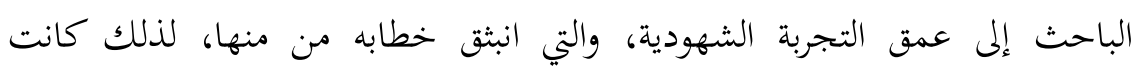

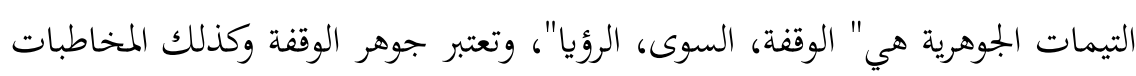
باعتبارها الوجه الآخر للوقفة.

\section{قائمة المراجع}

ابن منظور، جمال الدين (1997). لسان العرب. بيروت: دار صادر للنشر.

التلمساني، عفيف الدين (2007). شرح مواقف النفري. بيروت: دار الكتب العلمية. حنفي ، حسن (2009) من الفناء إلى البقاء ،ححاولة لإعادة بناء علم التصوف . بيروت:

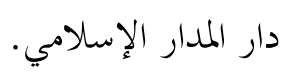

السخاوي، شمس الدين (1375هـ). المقاصد الحسنة في بيان الأحاديث المشتهرة. القاهرة:

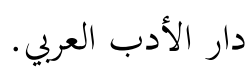

الفيروزآبادي، مجدالدين (2005). القاموس المحيط. بيروت: مؤسسة الرسالة للطباعة والنشر.

النفري، محمد (1985). المواقف والمخاطبات. القاهرة: الميئة المصرية للكتاب. 